\title{
Argon Broad Ion beam sectioning and high resolution scanning electron microscopy imaging of hydrated alite
}

\author{
Florian Kleiner, Christian Matthes, Christiane Rößler \\ F. A. Finger-Institute for Building Materials Science, Bauhaus-University Weimar, 99423 Weimar, Germany
}

\begin{abstract}
5 Scanning electron microscopy (SEM) imaging is able to visualize micro- to nano-structures of cement and concrete. A $\sim$ prerequisite is that the sample preparation preserves the native structure of the specimen. In this study, argon Broad of Ion Beam (BIB) sectioning is compared to state-of-the-art sample preparation (resin embedding, polishing) for hydrated $\exists$ alite. Additionally, it is investigated if during BIB, sample cooling is beneficial to avoid deterioration of cement hydrates. The aim is to quantitatively measure pore size distributions in hardened alite pastes.

Therefore, not only optimized sample preparation but also optimized imaging conditions are investigated. Finally, it is demonstrated that by image analysis pores down to a diameter of $5 \mathrm{~nm}$ in hydrated alite pastes can be quantitatively analysed.
\end{abstract}

- Keywords: Hydration, Alite, Argon broad ion beam, Electron microscopy, Surface preparation

\section{Introduction}

The preparation of smooth, flawless surfaces is an important prerequisite for high resolution scanning electron microscopy (SEM) and image analysis. Good quality images of cross sections are important for an easy image analysis and can be used as reference data to validate other techniques like mercury intrusion porosimetry or to calibrate results of proton nuclear magnetic resonance spectroscopy [1]. Furthermore, a very clean surface allows the collection of electron backscatter diffraction patterns, which provide valuable information about the crystalinity and the crystal orientation of minerals [2].

m Investigations of cement pastes and concrete samples

have been performed on specimens which were vacuum impregnated and embedded in low viscosity resins, ground and polished since the 1980 s till today $[3,4,5,6,7]$.

A clean and smooth surface of the sample without introducing artefacts like scratches is nearly impossible using $\checkmark$ abrasive diamond suspensions or polishing pads. This is

$\because$ especially the case, if a specimen contains minerals of different hardness [8] or is embedded in resin [9]. During mechanical polishing, the softer material (e.g. resin) is more easily removed and spread over the surface. These effects result in a bad feature resolution of the image. For material with low or unconnected porosity, resin impregnation is often not completely possible. As a result, subsequent sample preparation and imaging may be hindered or impossible.

Scrivener et al. described that it is possible to get a feature resolution of calcium silicate hydrate $(\mathrm{C}-\mathrm{S}-\mathrm{H})$ phases, ettringite and pores down to about 100 - $200 \mathrm{~nm}$ using con- ventional polishing techniques [6]. Therefore, especially phases with nano-scaled structures such as ettringite or C-S-H can not be differentiated by these techniques mainly because of damages due to mechanical preparation.
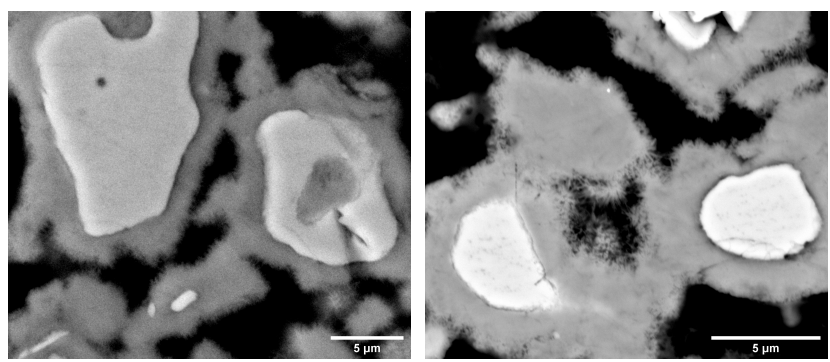

(a) Captured using an Everhart- (b) Captured using a modern Thornley detector in BSE mode diode BSE detector providing providing very few details. finer details.

Figure 1: High voltage $(15 \mathrm{kV}, 0.8 \mathrm{nA})$ BSE images by two different detectors of a $28 \mathrm{~d}$ hydrated alite specimen, mechanically polished, carbon coated.

In the past, backscatter electron (BSE) detectors only gave good image results at high voltages $(>10 \mathrm{kV})$, which further reduced the effective resolution (Figure 1(a)). Modern diode BSE detectors deliver a improved resolution (Figure 1(b)). Since the SEM detectors available today are able to work at low acceleration voltages, a conductive coating of samples is no longer a requirement in SEM imaging. The penetration depth of the electron beam at $1 \mathrm{kV}$ for the investigated materials is relatively low (Figure $2(\mathrm{a}))$. In combination with more sensitive BSE detectors the obtainable imaging resolution is improved [10] (chap- 
ter 4.6), but the preparation defects become very visible (Figure 2(b)).

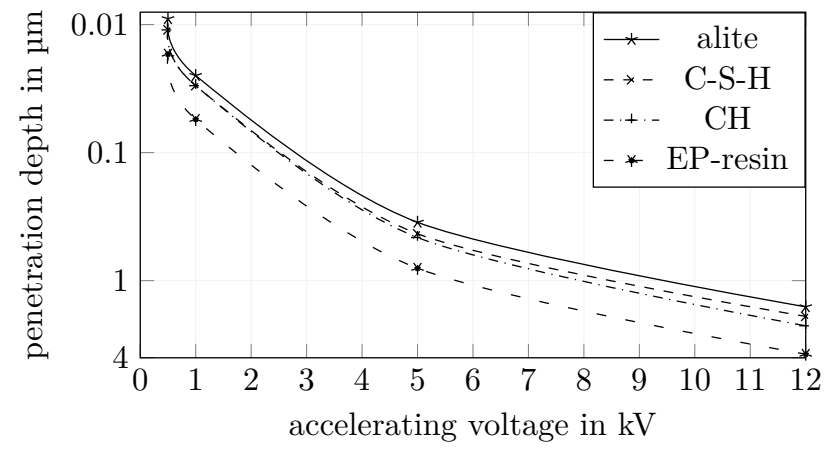

(a) Calculated penetration depths in different materials, modelled using the Electron Flight Simulator [11]

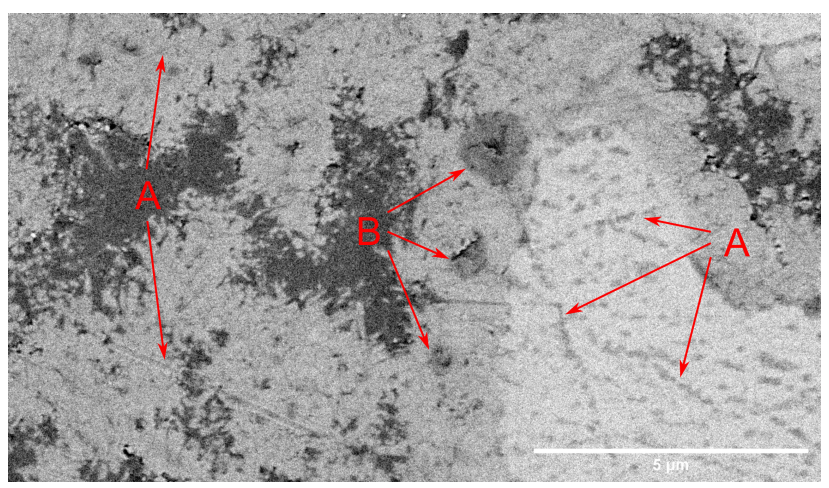

(b) A low voltage $(1.5 \mathrm{kV}, 0.8 \mathrm{nA}) \mathrm{BSE}$ image showing the surface damage (A: scratches, B: oil residue) due to mechanical polishing.

Figure 2: Visualization of the low penetration depth of the electron beam and sample-preparation defects that become visible at low acceleration voltage.

This study presents argon broad ion beam (BIB) sectioning $[12,13]$ as an alternative method to prepare cementitious specimen surfaces for SEM. In a BIB, accelerated ions are shot under a grazing angle of incidence on the specimen surface. A sharp tungsten blade makes it possible to erode the material in a controlled manner and to create a flat and smooth surface (Figure 3).

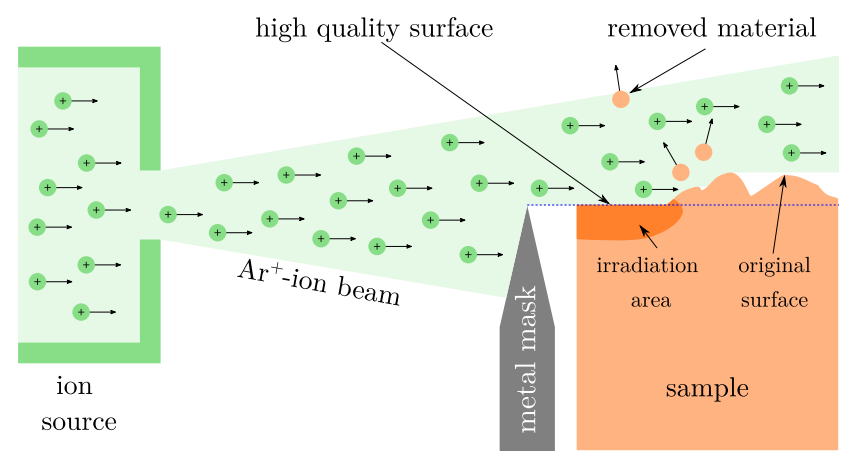

Figure 3: Principle of $\mathrm{Ar}^{+}$-broad ion beam milling, side view.
Specimens prepared using argon BIB have a polished surface with limited damage to the nano-scale features of interest and pores without debris [14, 9]. Furthermore, the necessity of resin intrusion is eliminated [14], while it is still possible [2] and in some cases feasible to do so.

C-S-H contains structural water and thus is known to undergo structural changes when exposed to high temperatures [15]. Argon BIB sectioning normally causes an increase in sample temperature [16]. Preparing C-S-H specimens for transmission electron microscopy (TEM) using a cooling stage was already proposed by Groves et al. [17] and Richardson et al. [18]. This proposal was strengthened by Viguier and Mortensen who calculated a theoretical temperature rise up to $673 \mathrm{~K}$ [19] in TEM lamellae and Park et al. measured up to $603 \mathrm{~K}$ in a thin TEM lamella [20]. Nevertheless, Groves et al. [17] were proposing, that there is no significant difference between the microstructure of hydrated alite prepared using normal and low-temperature conditions. It should be noted, that the respective images published by Groves et al. [17] show extensive damage in the pore structure of the inner C-S-H induced by the electron beam, which could mask the damages induced by the ion beam. Furthermore, for thin TEM lamellae the temperature increase due to ion beam polishing is expected to be different than for the approximately $5 \mathrm{~mm}$ thick bulk material that is BIB sectioned for large area SEM imaging. Thus, it could still be beneficial to use a cooling stage to prevent structural damage of the cement hydrates during BIB sectioning [21].

Desbois et al. presented the advantages of this method to visualize complex structures of e.g. clay stone [14] and sandstone [9] using BIB and cryo-BIB in combination with (cryo) focused ion beam (FIB). In contrast to FIB, BIB allows to prepare large sample areas in the range of a few square millimetres $[22,23]$ instead of typically 100 $200 \mathrm{\mu m}^{2}$ using FIB. In some cases cryo-BIB is even used as a tool for tomography $[23,24]$, while the slice thickness still is relatively large and inconsistent (min. $350 \mathrm{~nm} \pm 20 \%$ ) compared to FIB $(5-10 \mathrm{~nm})$ and the effort required is very high [23].

It is well known, that the electron beam tends to damage phases like C-S-H using TEM and SEM at high magnifications, due to thermal stress [18, 21]. Therefore, high resolution imaging of hydrated alite samples using SEM is only possible at low voltage and low beam current in order to avoid beam damage on hydrated phases.

The present study will demonstrate and discuss advantages and limitations of BIB sectioning for high resolution imaging and quantitative image analysis of hardened alite pastes. Typical irradiation artefacts, caused by the electron beam and the ion beam on this material are shown and their impact on image analysis is discussed. Additionally, possible solutions for their avoidance or correction methods are proposed. 


\section{Materials and methods}

\subsection{Experimental}

For all investigations, commercially available alite (M3 polymorph, Vustah, Czech Republic) was used. Its chemical composition, as shown in Table 1, was determined by $\mathrm{X}$-ray fluorescence spectroscopy (XRF).

Table 1: Chemical composition of alite measured by XRF.

\begin{tabular}{cc}
\hline Oxide & Alite [wt.-\%] \\
\hline $\mathrm{CaO}$ & 70.3 \\
$\mathrm{SiO}_{2}$ & 26.5 \\
$\mathrm{MgO}$ & 2.02 \\
$\mathrm{Al}_{2} \mathrm{O}_{3}$ & 0.34 \\
$\mathrm{P}_{2} \mathrm{O}_{5}$ & 0.13 \\
$\mathrm{Fe}_{2} \mathrm{O}_{3}$ & 0,07 \\
$\mathrm{Na}_{2} \mathrm{O}$ & 0.04 \\
$\mathrm{~K}_{2} \mathrm{O}$ & 0.03 \\
$\mathrm{TiO}_{2}$ & 0.03 \\
$\mathrm{Mn}_{2} \mathrm{O}_{3}$ & 0.02 \\
$\mathrm{LOI}$ & 0.46 \\
\hline$\sum$ & 99.8 \\
\hline
\end{tabular}

The specimens were prepared in a nitrogen filled glovebox to prevent carbonation. Alite with a mean particle size of $10 \mu \mathrm{m}$ was mixed with water $(w / s=0.5)$ and filled into sample moulds $(7 \times 7 \times 50 \mathrm{~mm})$. The specimens were cured for 1, 7 and 28 days in the same glovebox. After this time, the alite reaction was stopped by immersing the prisms in ethanol (98\%) for 20 minutes. The specimens were dried at $40{ }^{\circ} \mathrm{C}$ and then saw cut using a target surfacing system (EM TXP, Leica). Some specimens were polished using sandpaper / diamond polishing paste from 1.0 to $0.5 \mu \mathrm{m}$ in the same device. Since alite is sensitive to water, the preparation process was done using ethanol as rinsing solution. Afterwards, the sample was dried in a vacuum chamber. To obtain images of fractured surfaces of the $24 \mathrm{~h}$ hydrated specimen, the prisms were cracked using pliers until they were small enough to fit on a SEMsample holder.

Furthermore, some of the samples shown in this study were embedded in low viscosity epoxy-resin (resin R1370, hardener R1376, Agar Scientific) by immersing a $7 \times 7 \times 3 \mathrm{~mm}$ sample-section in resin, followed by degassing in two 30 minute cycles. Subsequently, the specimen was removed from the still uncured resin and placed face-down on a glass surface and cured at $40^{\circ} \mathrm{C}$ in an oven.

Using standard mechanical polishing, sections were polished in incremental steps with diamond oil slurries of particle sizes $15,3,1$, and $0.25 \mu \mathrm{m}$. Carbon coating of approx. $8-10 \mathrm{~nm}$ thickness was applied on selected samples (SCD 500 , Baltec).

The dried and polished 7 and $28 \mathrm{~d}$ alite samples were transferred into a triple ion beam milling system (EM TIC 3X, Leica). Argon BIB sectioning is carried out under vacuum (10 to 40 mbar) conditions. The three argon ion beams intersect at a sharp edged tungsten mask forming a milling sector of approximately of $100^{\circ}$ (Figure 3 ). The mask and the specimen surface are arranged in a way that only $20-100 \mu \mathrm{m}$ of the sample are exposed to the ion beam above the mask.

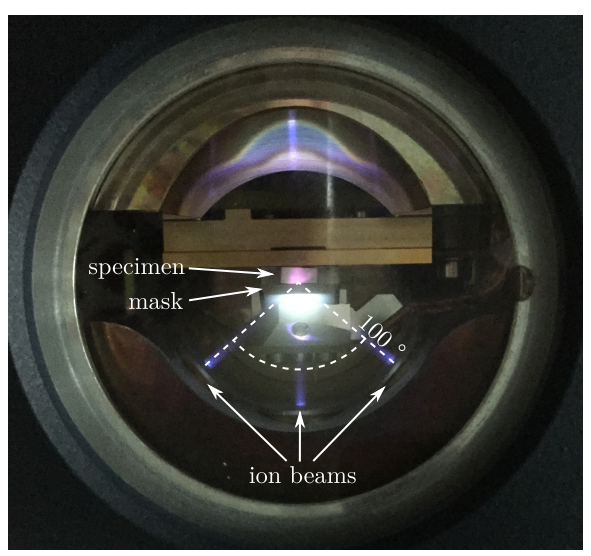

Figure 4: Milling of a specimen. The ion beams appear as violetblueish rays.

The BIB system used, allows to cool the specimen using liquid nitrogen to $-140{ }^{\circ} \mathrm{C}$ during the milling process. The process gas was argon with a purity of $99.999 \%$. The examined samples were initially prepared using an acceleration voltage of $6 \mathrm{kV}$ and $2 \mathrm{~mA}$ gun current for 3 hours for the bulk milling. Afterwards, the parameters were changed to $3 \mathrm{kV}, 1 \mathrm{~mA}$ for another 3 hours as a polishing step. The same parameters were used without cooling to compare both preparation methods. An area of up to one $\mathrm{mm}^{2}$ can be analysed afterwards as shown in Figure 5.

The uncoated, as-prepared surface of all samples was characterized using an ultra high resolution SEM (Helios G4 UX DualBeam, thermoFischer Scientific and Nova Nano SEM 230, FEI). The images shown are acquired using the through-the-lens detector (TLD) in secondary electron detection (SE) or in BSE mode. For the high resolution imaging using the TLD-SE (high vacuum), the SEMimmersion mode was used. In some cases these settings were combined with a stage bias and a monochromator. These settings allow the observation of pores structures of hydrated alite at nano-scale resolution.

\subsection{Semi automatic segmentation}

To segment a statistically relevant amount of pores using the acquired images, a segmentation by hand, using arbitrary thresholds is not suitable. Therefore, the image analysis was performed using a custom-written python script [25]. The half-automated process automatically determines the scale and denoises the SE images of hydrated alite cross sections using non-local-means filtering [26].

To relate the segmented pores to a phase like C-S-H, it is necessary to segment these phases. In many cases, 

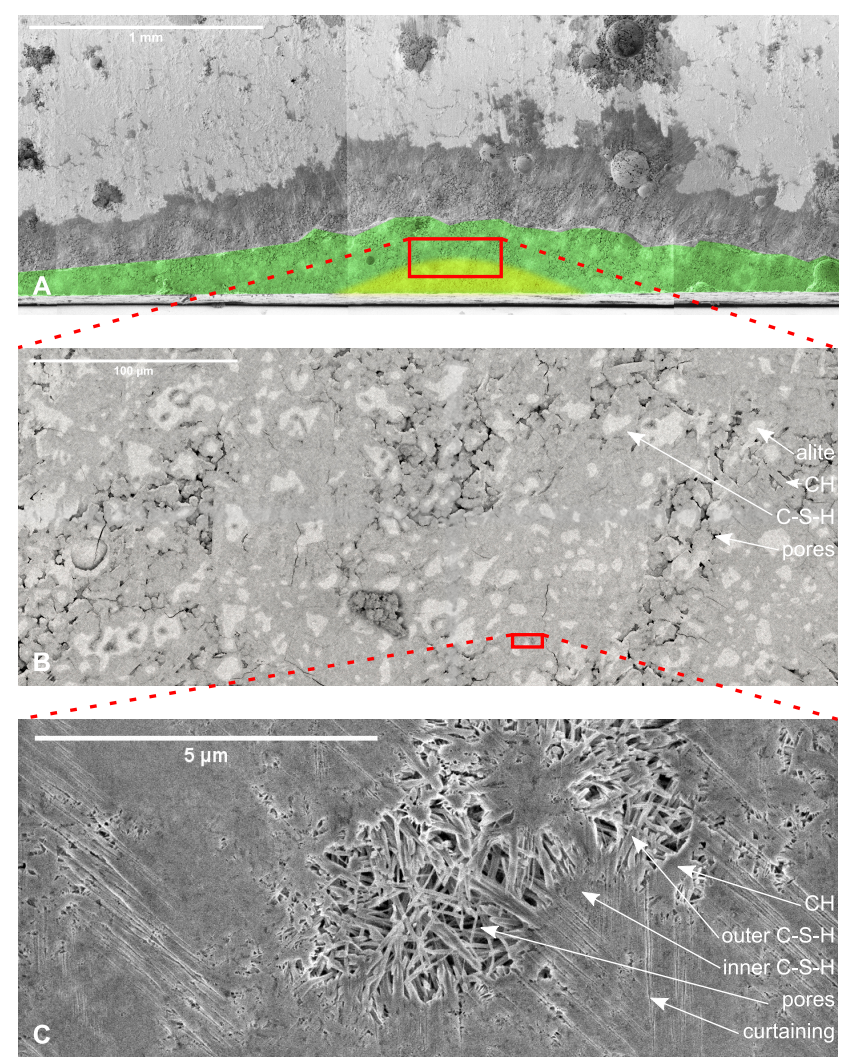

Figure 5: Surface of 28 days hydrated alite $(7.0 \times 2.5 \mathrm{~mm})$ prepared using cryo-BIB (same specimen orientation as shown in Figure 3. The area used for SEM imaging (approx. $0.99 \mathrm{~mm}^{2}$ ) is tinted green. Images A and B are large area, high resolution BSE images composed of multiple individual images. The lower image $\mathrm{C}$ shows a SE image with typical morphology of fibrous outer $\mathrm{C}-\mathrm{S}-\mathrm{H}$ phases and dense inner C-S-H. Furthermore, some stripes caused by the BIB process (curtaining) are visibile.

the gray values of the solid phases like $\mathrm{C}-\mathrm{S}-\mathrm{H}, \mathrm{CH}$ and alite are very similar or even overlapping. Therefore, the script offers a method for manual segmentation, to mark areas that should be excluded from the analysis (eg. other phases, large pores or image and preparation artefacts).

Overflow based algorithms for pore segmentation as proposed by Wong et al. [27] result in a global threshold value for an image. They require fairly distinct brightness differences between the object of interest (pores) and the surrounding areas (C-S-H). Furthermore it is assumed, that pores and background have no overlapping gray values within the image. As shown in Figure 6(a) this does not apply for the TLD-SE images of dense inner C-S-H. This becomes more obvious in Figure 6(b) with an enhanced contrast and also in the narrow histogram in Figure 6(c). Applying a global threshold on such images will result in a significant over-segmentation or no segmentation at all, if other phases or large pores are included in the image. Figure 6(d) shows the segmentation results based on threshold values determined by algorithm proposed by Shanbhag [28].

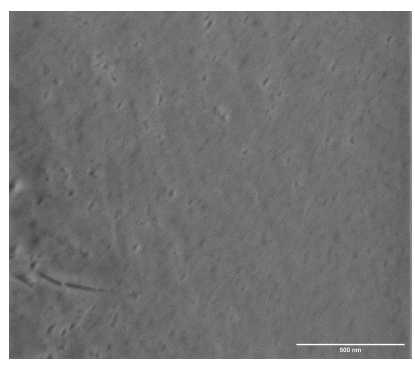

(a) Source image

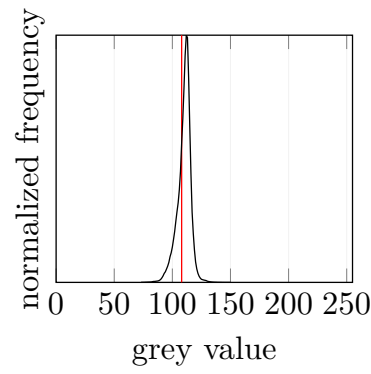

(c) Image histogram and thresh- (d) Resulting segmentation (red) old at 108

Figure 6: Illustration of the usage of a global threshold value on the image of dense inner C-S-H of $28 \mathrm{~d}$ hydrated alite prepared using BIB at $20^{\circ} \mathrm{C}$. TLD-SE, $2 \mathrm{kV}, 89 \mathrm{pA}$

Therefore, the pores within the alite are segmented using the local thresholding algorithm proposed by Phansalkar et al. [29]. It is derived from the Sauvola thresholding method [30], but modified to deal especially with low contrast images as shown in Figure 6(a). The algorithm calculates a threshold in a given window radius (e.g. $20 \mathrm{px}$ ) to segment the pores instead of using a single thresholding 
value for the whole image. Phansalkar thresholding is implemented in the python script but also easily accessible in the the Auto Local Threshold function of Fiji (ImageJ) [31], delivering results comparable to the python script using the parameters $k=0.15$ and $r=0.3$. After the application of morphological operators to denoise the binary images, a pore size distribution (PSD) refereed to the surrounding phase or to the whole image can be calculated. Since a single image very often contains very few pores, a PSD delivers a very noisy result due to a low pore count. Therefore, also the chord-length density function (CDF) [32] (chapter 2.5) is calculated in $x$ - and $y$-directions for every pixel row and column to improve the data density. The CDF is derived from the measurement of the chord lengths between the intersection of two-phase interfaces. In this case the chords within a pore are measured and plotted in a histogram. For all calculations the pores are considered to be circular.

\section{Results and discussion}

The goal of this investigation was to achieve high resolution images of hydrated alite with as little influence of the preparation steps. Figure 7 shows such images using fractured surfaces of a $28 \mathrm{~d}$ hydrated alite as an example.

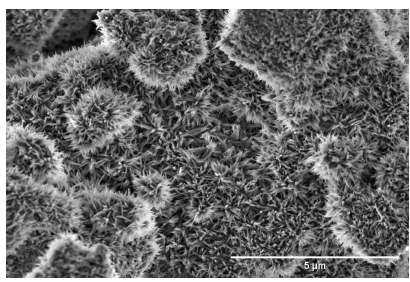

(a) $24 \mathrm{~h}$ hydrated alite

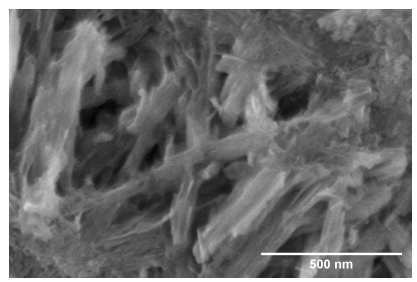

(b) $28 \mathrm{~d}$ hydrated alite
Figure 7: Fractured surfaces of hydrated alite specimens. Acquisition parameters: TLD-SE, left: $2 \mathrm{kV}, 7 \mathrm{pA}$, right: $4 \mathrm{kV}, 1.25 \mathrm{nA}$, stage bias $2 \mathrm{kV}$, immersion mode, high vacuum.

The C-S-H-needles are clearly visible and due to the low magnification in Figure 7(a), no significant deformation of the microstructure due to the high vacuum can be seen. This is supported by similar images acquired using a low vacuum SEM by Stark et al. [33]. According to findings by Gajewicz et al. [34], drying at $60^{\circ} \mathrm{C}$ causes changes in the water saturation and the size of gel pores of the C-S-H. Therefore, it may be possible that there are changes within the microstructure at the nano-scale. Nevertheless, Figure 7 (b) shows no immediate signs of nano- and micro-cracks due to vacuum drying and SEM imaging. Therefore it is assumed that these images represent a close-to native view of the C-S-H microstructure.

However, it is not possible to process any pore analysis on an undefined rough surface. Therefore, the proposed preparation method using BIB is applied to these specimens. While utilizing BIB can produce good results as

shown in Figure 8, some artefacts inherent to this method will be discussed in the following sections.

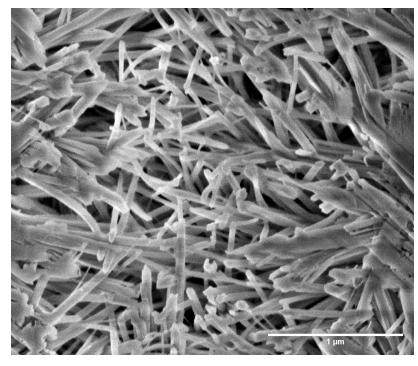

(a) C-S-H needles $(2 \mathrm{kV}, 22 \mathrm{pA})$

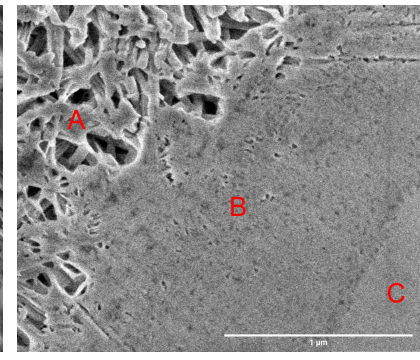

(b) A: Outer C-S-H, B: inner C-S-H, C: unhydrated alite $(1.5 \mathrm{kV}, 6.8 \mathrm{pA})$

Figure 8: SE images of $28 \mathrm{~d}$ hydrated alite without visible preparation artefacts after argon BIB sectioning.

\subsection{Effect of low voltage $S E M$ on $C-S-H$}

Due to the high water content, the electrical nonconductivity and the delicacy of the C-S-H needles, electron and ion beams can alter the shape of such components of the microstructure as needles and pores. Even very low accelerating voltages and beam currents can induce damages to the needle-shaped structures of C-S-H in a manner of a few seconds. As can be seen in Figure 9, the C-S-H needles start to bend or melt starting from the tip when they are exposed to an electron beam of $350 \mathrm{~V}$ and $25 \mathrm{pA}$ for about $60 \mathrm{~s}$. This is a direct consequence of the high energy density applied during the high resolution scanning.

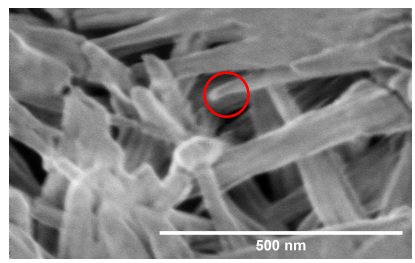

(a) Initial images before final focus

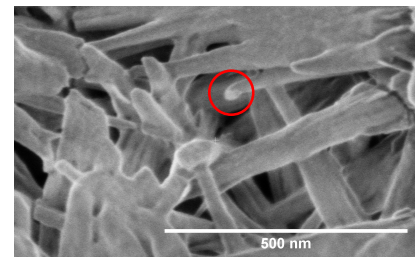

(b) Final focused image, $60 \mathrm{~s}$ afterwards
Figure 9: Electron beam damaged C-S-H needle at $350 \mathrm{~V}$ accelerating voltage and a stage bias of $200 \mathrm{~V}$. The left image was captured directly after moving to the position. The right image was captured $60 \mathrm{~s}$ after the left image and a continuous electron beam exposure. A 5-frame-animation is also available [35].

Furthermore, pores within the dense C-S-H-Phase seem to grow if the electron beam scans an area for a longer time period. This can be seen in the marked area of Figure 10, where the electron beam stayed for 1-2 minutes to focus. A comparable phenomenon has been observed by Rößler et al. [21] and Rossen [36] using a TEM.

\subsection{Typical artefacts caused by argon BIB}

An ion beam is much more destructive than an electron beam and may induce a thermally damaged volume 


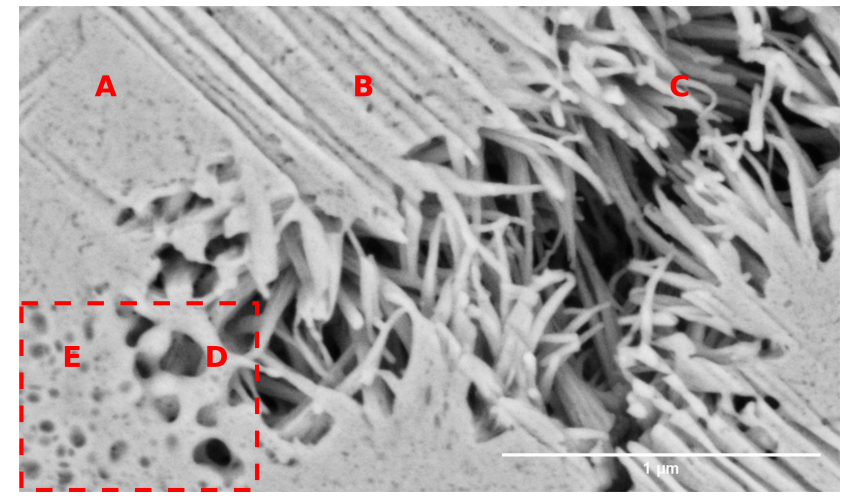

Figure 10: C-S-H with signs of various radiation damages. Undamaged pore structure (A), curtaining caused by BIB (B), deformed $\mathrm{C}-\mathrm{S}-\mathrm{H}-$ needles caused by BIB at $20^{\circ} \mathrm{C}$ (C) and and by prolonged focusing of the electron beam (D), altered pore structure by focussing of the electron beam (E). (TLD-BSE, $2 \mathrm{kV}, 50 \mathrm{pA}$ )

near the prepared surface [18]. Figure 10 (Area C) visualizes the deformation of the $\mathrm{C}-\mathrm{S}-\mathrm{H}$ needles after the BIB preparation, especially in peripheral areas of the specimen or in very large pores. As can be seen in Figure 11, the $\mathrm{C}-\mathrm{S}-\mathrm{H}$ phases are damaged in larger pores after the BIB application. This seems to be caused by the deposition of material eroded from the surface of the sample and the tungsten blade.

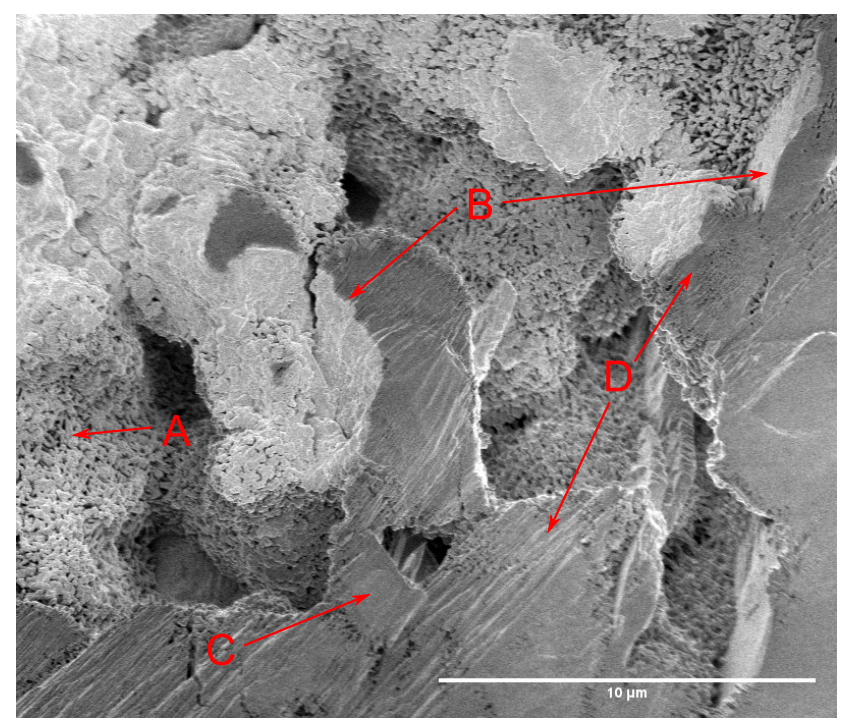

Figure 11: Material eroded by the BIB sectioning process deposits in a larger pore of a specimen. A: Exposed C-S-H needles seem to agglutinate due to coating with redeposited material. B: Bright deposition layer containing tungsten (approximately $200 \mathrm{~nm}$ thick). C: faintly visible alite grain, D: hydrates like C-S-H and CH. (TLD beam deceleration mode, $500 \mathrm{~V}, 6.3 \mathrm{pA}$, stage bias $200 \mathrm{~V}$, immersion mode)

Another explanation for this appearance could be, that the tips of the C-S-H phases melt. This seems unlikely, since the C-S-H needles directly at the surface or in smaller pores don't seem to be greatly affected after BIB sectioning.

Neither the specimen nor the ion sources are moveable in the used configuration of the ion beam device. Therefore, the specimen shows some artefacts known as curtaining (also known as waterfall effect) [37, 24]. As there were no corresponding damages to the tungsten blade, this effect has to be caused by different material densities and therefore varying resistance levels to the ion beam within the sample material. Since three ion beams erode the surface, also multiple curtaining directions occur as can be seen in Figure 12(a).

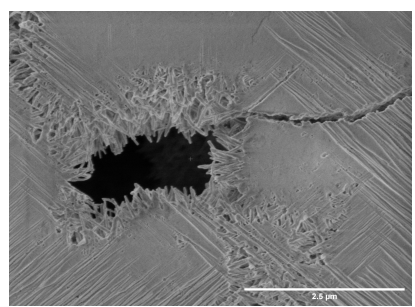

(a) Curtaining artifacts spread over the the surface.

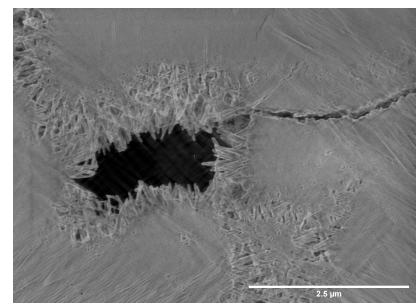

(b) Removed curtaining effect using FFT in both directions.
Figure 12: Alite specimen (cured for 7 days) after cryo-BIB milling. (TLD-SE, $1 \mathrm{kV}, 3.1 \mathrm{pA}$, stage bias $500 \mathrm{~V}$, immersion mode)

The effect can be diminished using Fast Fourier Transformation (FFT) based filtering provided in the open source software package Fiji [31]. This process reduces the quality of the image, but makes it much easier to set a threshold for image binarization (compare Figure 13). To limit the loss of image quality, in most cases only one direction of curtaining marks should be removed. Nevertheless, imaging area with as little curtaining as possible is preferable to any post-processing.

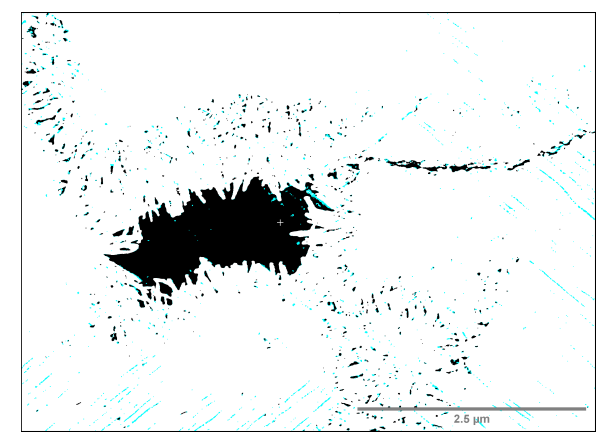

Figure 13: Thresholding results of Figure 12 (Auto Local Threshold, method Phansalkar [29]). white: segmented pores of Figure 12(a).; blue: additional areas which were segmented due to curtaining in Figure 12(a).

As can be seen in Figures 8(a) and 12(a) the C-S-Hphases are still intact after 6 hours of argon BIB application. Also small pores and fibre structures are still visible. 


\subsection{Resin embedding}

Whereas BIB makes high quality surfaces possible while maintaining structures sensitive to higher temperatures or mechanical stress, it can be hard to correctly segment pores in an automated process. It is not practical to prepare infinitely thin specimens for SEM investigations. Therefore, the pore background of non-embedded samples is often visible (Figures 8(a) and 14(a)).

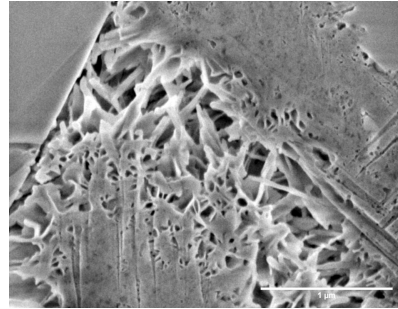

(a) Raw image, TLD-SE, $2 \mathrm{kV}$, $14 \mathrm{pA}$

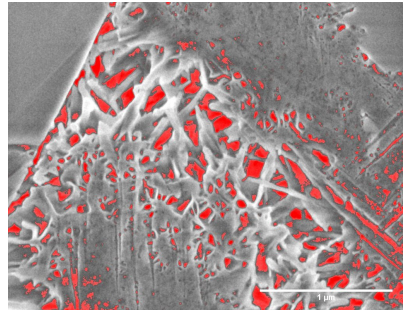

(b) Segmented image (manual thresholding)
Figure 14: $7 \mathrm{~d}$ hydrated alite, segmented pores of porous outer C-S-H.

This leads to an incorrect segmentation of pores in the image analysis. In this case, the pore size is significantly underestimated and therefore, too many pores are recognized (Figure 14).

A possibility to avoid this problem is to embed the the specimen in a low viscosity resin to fill the pores. Resin embedded specimens are as easy to polish using argon BIB at room temperature as resin free specimens. As shown in Figure 15, the visibility of the pore background of large pores is significantly reduced due to the embedding.

Due to the applied low acceleration voltage for imaging, mainly surface features are visible in SE mode, while the obtainable material contrast is very low. While the trained human eye may be able to differentiate between resin filled pores and the alite/C-S-H-phases, it is difficult to automatically segment those low contrast images. In comparison, images made using BSE benefit from the high material contrast and the flat surface (Figure 15). Therefore, resin embedding is especially useful for the analysis of larger pores (i.e. $>25 \mathrm{~nm}$ diameter) using high resolution BSE-imaging.

\subsection{Pore analysis}

To determine the damage induced due to thermal stress during the BIB process at room temperature, it was compared against cryo-BIB. Since subjectively no alteration of C-S-H structures in high resolution images after both preparation methods could be found, a pore analysis for the dense inner C-S-H (definition as proposed by Tennis and Jennings [38]) was carried out.

Figures 16 and 17 show nano-size pores of a sample sectioned using BIB at -140 or $20^{\circ} \mathrm{C}$. All images show dense inner C-S-H of $28 \mathrm{~d}$ hydrated alite (as in Figure 15(a), upper left quadrant). Pores with a diameter of $5 \mathrm{~nm}$ can be

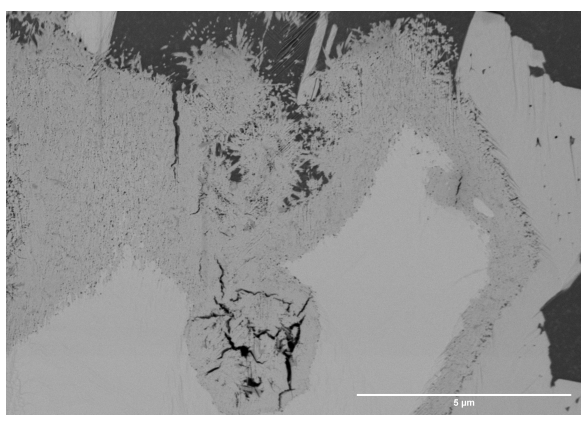

(a) Overview image, TLD-BSE, $1 \mathrm{kV}, 0.1 \mathrm{nA}$

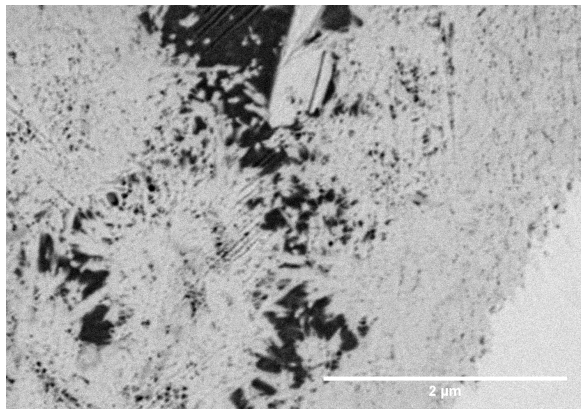

(b) Detail view of Figure 15(a) showing very good contrast of larger pores and presence of nano-scaled pores in inner C-S-H

Figure 15: BSE images of $7 \mathrm{~d}$ hydrated alite embedded in resin, polished using cryo-BIB.

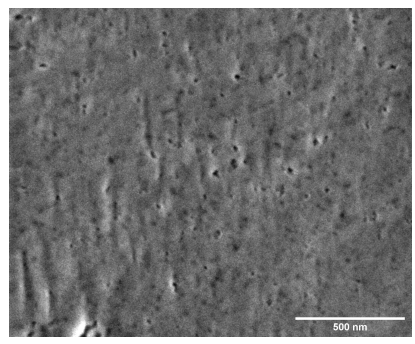

(a) Raw image (TLD-SE, $2 \mathrm{kV}$, $77 \mathrm{pA})$

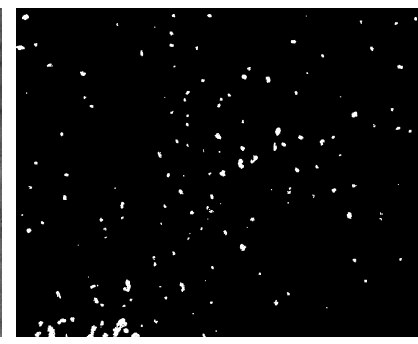

(b) Segmented pores

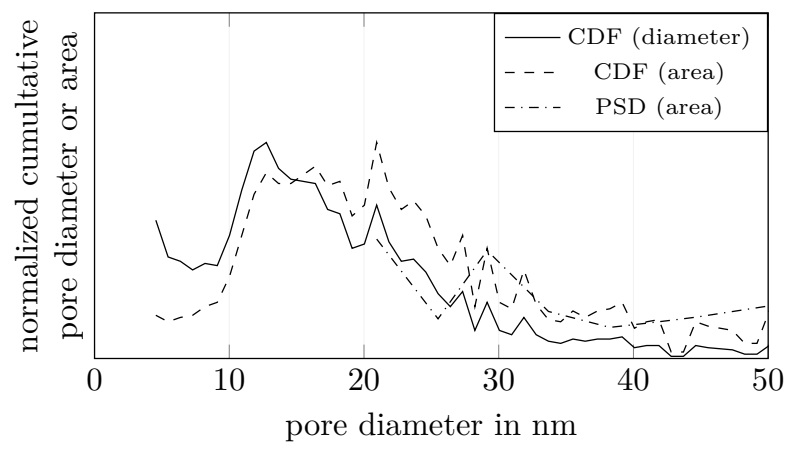

(c) CDF and PSD plot

Figure 16: PSD of dense inner C-S-H (28 d hydrated alite) obtained from SE image analysis (BIB at $-140^{\circ} \mathrm{C}$ ). 


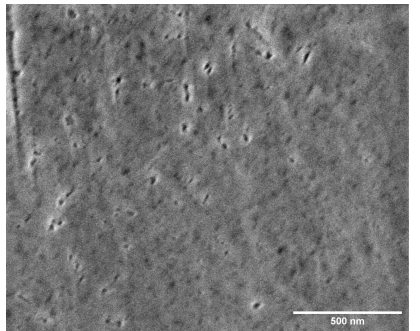

(a) Raw image (TLD-SE, $2 \mathrm{kV}$, $89 \mathrm{pA})$

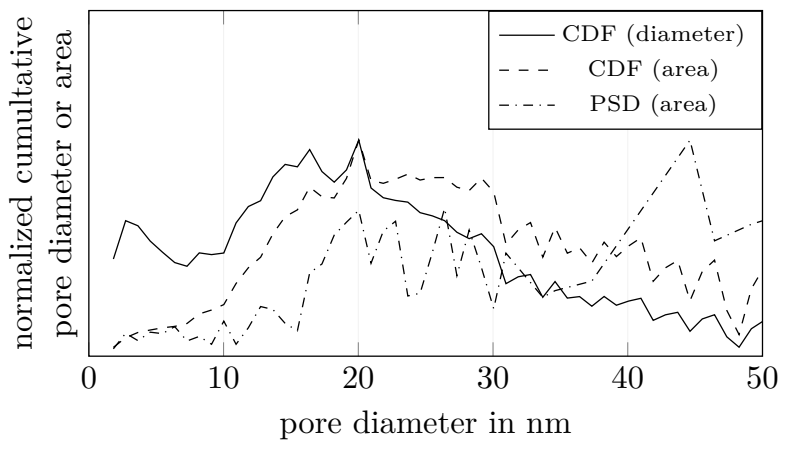

(c) CDF and PSD plot

Figure 17: PSD of dense inner C-S-H (28 d hydrated alite) obtained from $\mathrm{SE}$ image analysis (BIB at $20^{\circ} \mathrm{C}$ ).

clearly distinguished and analysed in the SE-images (resolution: $0.9 \mathrm{~nm}$ per px, $2022 \times 1650)$. As shown in Figures $16(\mathrm{~b})$ and $17(\mathrm{~b})$, the images are segmentable using the afore mentioned method. Nevertheless, since it is still possible that the segmentation method may falsely detect some microstructural features, such as pores, the results should be checked manually and the areas with a erroneous segmentation should be excluded.

As can be seen in Figures 16(c) and 17(c), the CDF (converted from chord to area, dashed), shows a different distribution than the PSD, determined by the analysis of the pore areas (dash-dotted line). Comparing these graphs, it becomes clear, that the PSD has very different gradients and is very noisy. It is also dependent on the background noise of the image (compare Figures 16(c) and 17(c)), while the CDF provides more stable results. The CDF analysis shows that the pores inside the C-S-H have a diameter of mainly 10 to $30 \mathrm{~nm}$. However, these results base on single images and only illustrate the quality of the preparation method.

For each method (BIB at -140 or $20^{\circ} \mathrm{C}$ ), seven images were analysed using the presented process. These images and the results can be found in the supplementary data. Since the pixel size and the image areas differed slightly, the images were analysed individually. The position of the mean peak value of the CDF was used to compare both methods. As presented in Table 1 in the supplementary attachment, the mean peak value for BIB at $-140^{\circ} \mathrm{C}$ is at a pore diameter of $17.5 \pm 2.8 \mathrm{~nm}$ and at a pore diameter of $22.7 \pm 5.4 \mathrm{~nm}$ for BIB at $20^{\circ} \mathrm{C}$. Furthermore, Figures 16(a) and 17(a) show no obvious difference in pore structure. The detected variation in the CDF between both methods is negligible and in the opinion of the authors more dependent on the position and quality of the captured images. This was confirmed by preparing alite specimens with different BIB treatment times $(3$ or $6 \mathrm{~h})$ and voltages $(3$ or $6 \mathrm{kV})$ at $-140^{\circ} \mathrm{C}$ and at $20^{\circ} \mathrm{C}$. Instead, different surface qualities were found, at increasing distances from the crossover area of the three argon ion beams. Nano pores, as shown in Figures 16(a) and 17(a), can be found especially in the green area marked in Figure 5A, while in the yellow area these pores are rarely visible or covered by artefacts. This was discovered in specimens treated at room temperature but also in cooled specimens.

\section{Conclusions}

Argon broad ion beam sectioning is widely used to prepare samples containing materials of varying hardness for SEM imaging. This study has shown that it is also applicable for sensitive materials like 7 and $28 \mathrm{~d}$ hydrated alite.

In contrast to typically presented SEM images, specimens obtained using the BIB sectioning (at room temperature and $-140^{\circ} \mathrm{C}$ ) show flat, high quality surfaces with minor alterations. Similar to FIB serial sectioning, curtaining and redeposition of material can be found using argon BIB. These features are not visible for every specimen or only in limited areas which can be excluded for image analysis. Artefacts like curtaining are introduced using stationary sample holders, but are reducible by various image filters with a certain loss of image resolution.

C-S-H structures observed after cryo and room temperature BIB sectioning are very similar, which is in accordance to the findings of Groves et al. [17] based on sample preparation for TEM imaging. The structural variation is masked by the damages caused by the electron beam of the SEM, which, depending on the acceleration voltage and beam current, can induce significant changes to the morphology of inner and outer $\mathrm{C}-\mathrm{S}-\mathrm{H}$ phases. The results indicate, that on all investigated surfaces prepared using BIB sectioning, very small pores of about $5 \mathrm{~nm}$ diameter can be visualized using the TLD-SE mode. This was already proposed for BSE-images utilizing Monte Carlo simulations by Yio et al. [39].

When performed at the temperature of $-140{ }^{\circ} \mathrm{C}$, the BIB method is more involved, and more time consuming than when it is performed at room temperature. It can also be concluded that, regardless of the preparation temperature, the obtained pore size distribution of the C-S-H will be similar as long as the BIB accelerating voltage is kept within the range of $3 \mathrm{kV}$ to $6 \mathrm{kV}$. However, this conclusion may not hold for higher values of accelerating voltages.

The surfaces prepared using BIB sectioning can be used for image analysis to determine the pore size or the phase 
distribution. Nevertheless, due to the small size of the area analysed, BIB sectioning as described in this paper is only applicable to statistically analyse a limited range of feature sizes. For more heterogeneous samples like mortar or even concrete it can still provide a qualitative insight into the material, and quantitative-type observations for nano-meter sized features.

The good quality of the surface of BIB sections of hydrated alite allowed for the high resolution SEM images. The imaging resolution is thereby depending mainly on the resolution of the microscope. The highest resolution was obtained using the SEM immersion mode, modern in-lens $\mathrm{BSE}$ and SE detectors at low acceleration voltage (0.3 to $4.0 \mathrm{kV})$.

Quantification of PSD on SEM images may be beneficial to improve the basic understanding of transport mechanisms in concrete. In this study this was demonstrated using a limited number of images.

Furthermore, It must be noted that the PSD determined in this study is based on data derived from 2D-images. A comparison with volumetric porosity measurements would require a transformation of the data, which is beyond the scope of the present work. Another approach could be serial sectioning and 3D-imaging using argon BIB as shown by Desbois et al. [23]. Nevertheless, the BIB section thickness achieved by Desbois et al. (>350 nm) [23] is much larger than the pores segmented in this study $(5 \mathrm{~nm})$. This leads to the conclusion that argon BIB is ideally combined with FIB-SEM to obtain high resolution volumetric data [40, 41].

For future studies, considerably more images have to be segmented and analysed to be able to make statistically reliable statements considering the PSD in individual phases of hydrated alite. Furthermore, the effects of this preparation method on hydrated Portland cement specimens should be studied. For those types of specimens, using cooled-stage BIB might still be relevant as it will allow to preserve cement hydrates such as ettringite, which contain more structural water than C-S-H.

\section{Acknowledgment}

The research was supported by the Deutsche Forschungsgemeinschaft (DFG), grant number 344069666 .

\section{References}

[1] C. Naber, F. Kleiner, F. Becker, L. Nguyen-Tuan, C. Rößler, M. A. Etzold, J. Neubauer, C-S-H Pore Size Characterization Via a Combined Nuclear Magnetic Resonance (NMR) - Scanning Electron Microscopy (SEM) Surface Relaxivity Calibration, Materials (Basel, Switzerland) 13 (7) (2020). doi:https: //doi.org/10.3390/ma13071779.

[2] C. Rößler, B. Möser, H.-M. Ludwig, 13. Characterization of microstructural properties of Portland cements by analytical scanning electron microscopy, in: H. Pöllmann (Ed.), Cementitious Materials, De Gruyter, Berlin, Boston, 2017, pp. 379-422. doi:https://doi.org/10.1515/9783110473728-014.
[3] K. L. Scrivener, P. L. Pratt, Backscattered electron images of polished cement sections in the scanning electron microscope, Proceedings of the International Conference on Cement Microscopy (1984).

[4] K. O. Kjellsen, R. J. Detwiler, O. E. Gjørv, Backscattered electron imaging of cement pastes hydrated at different temperatures, Cement and Concrete Research 20 (2) (1990) 308-311. doi:https://doi.org/10.1016/0008-8846(90)90085-C.

[5] K. Kjellsen, A. Mons $\varnothing y$, K. Isachsen, R. Detwiler, Preparation of flat-polished specimens for SEM-backscattered electron imaging and X-ray microanalysis - importance of epoxy impregnation, Cement and Concrete Research 33 (4) (2003) 611-616. doi: https://doi.org/10.1016/S0008-8846(02)01029-3.

[6] K. L. Scrivener, Backscattered electron imaging of cementitious microstructures: understanding and quantification, Cement and Concrete Composites 26 (8) (2004) 935-945. doi:https://doi. org/10.1016/j.cemconcomp.2004.02.029.

[7] C. Hu, H. Ma, Statistical analysis of backscattered electron image of hydrated cement paste, Advances in Cement Research 28 (7) (2016) 469-474. doi:https://doi.org/10.1680/jadcr. 16.00002 .

[8] G. Ji, Z. Tan, R. Shabadi, Z. Li, W. Grünewald, A. Addad, D. Schryvers, Di Zhang, Triple ion beam cutting of diamond/Al composites for interface characterization, Materials Characterization 89 (2014) 132-137. doi:https://doi.org/10.1016/j. matchar.2014.01.008.

[9] G. Desbois, F. Enzmann, J. L. Urai, C. Baerle, P. A. Kukla, J. Konstanty, Imaging pore space in tight gas sandstone reservoir: insights from broad ion beam cross-sectioning, EPJ Web of Conferences 6 (2010) 22022. doi:https://doi.org/10.1051/ epjconf $/ 20100622022$.

[10] D. C. Bell, N. Erdman, Low voltage electron microscopy: Principles and applications, Royal Microscopical Society-John Wiley series, John Wiley \& Sons Inc. in association with the Royal Microscopical Society, Chichester, West Sussex, 2013.

[11] Small World, Electron Flight Simulator (2004).

[12] J. M. E. Harper, J. J. Cuomo, Material Processing with BroadBeam Ion Sources, Annual Review of Materials Science 13 (1) (1983) 413-439. doi:https://doi.org/10.1146/annurev.ms . 13.080183.002213.

[13] W. Grünewald, Ionenstrahlätzanlage zur Präparation von Proben für die Elektronenmikroskopie, Wissenschaftliche Zeitschrift der Technischen Hochschule Karl-Marx-Stadt 29 (4) (1987) 521-526.

[14] G. Desbois, J. L. Urai, P. A. Kukla, Morphology of the pore space in claystones - evidence from BIB/FIB ion beam sectioning and cryo-SEM observations, eEarth 4 (1) (2009) 15-22. doi:https://doi .org/10.5194/ee-4-15-2009.

[15] E. Tajuelo Rodriguez, K. Garbev, D. Merz, L. Black, I. G. Richardson, Thermal stability of C-S-H phases and applicability of Richardson and Groves' and Richardson C-(A)-S-H(I) models to synthetic C-S-H, Cement and Concrete Research 93 (2017) 45-56. doi:https://doi.org/10.1016/j.cemconres.2016.12. 005.

[16] Y.-W. Kim, K.-W. Yi, Estimation of Temperature Rise During Ion Milling of Samples, Microscopy and Microanalysis 9 (S02) (2003) 796-797. doi:https://doi.org/10.1017/ S1431927603443985.

[17] G. W. Groves, P. J. Sueur, W. Sinclair, Transmission Electron Microscopy and Microanalytical Studies of Ion-Beam-Thinned Sections of Tricalcium Silicate Paste, Journal of the American Ceramic Society 69 (4) (1986) 353-356. doi:https://doi.org/ 10.1111/j.1151-2916.1986.tb04746.x.

[18] I. G. Richardson, G. W. Groves, Microstructure and microanalysis of hardened ordinary Portland cement pastes, Journal of Materials Science 28 (1) (1993) 265-277. doi:https: //doi .org/10.1007/BF00349061.

[19] B. Viguier, A. Mortensen, Heating of TEM specimens during ion milling, Ultramicroscopy 87 (3) (2001) 123-133. doi :https: //doi.org/10.1016/s0304-3991(00)00095-4.

[20] Y. M. Park, D.-S. Ko, K.-W. Yi, I. Petrov, Y.-W. Kim, Mea- 
surement and estimation of temperature rise in TEM sample during ion milling, Ultramicroscopy (2007) 663-668doi:https: //doi.org/10.1016/j.ultramic.2007.01.002.

[21] C. Rößler, J. Stark, F. Steiniger, W. Tichelaar, Limited-Dose Electron Microscopy Reveals the Crystallinity of Fibrous CS-H Phases, Journal of the American Ceramic Society 89 (2) (2006) 627-632. doi:https://doi.org/10.1111/j.1551-2916. 2005.00714.x.

[22] W. Hauffe, S. Menzel, T. Göbel, Advantages of Broad Ion Beam (BIB) Processing Compared with Focused Ion Beam (FIB) Technology for 3D Investigation of Heterogeneous Solids, Microscopy and Microanalysis 9 (S03) (2003) 148-149. doi:https : //doi.org/10.1017/S1431927603016106.

[23] G. Desbois, J. L. Urai, F. Pérez-Willard, Z. Radi, S. Offern, I. Burkart, P. A. Kukla, U. Wollenberg, Argon broad ion beam tomography in a cryogenic scanning electron microscope: a novel tool for the investigation of representative microstructures in sedimentary rocks containing pore fluid, Journal of microscopy 249 (3) (2013) 215-235. doi:https://doi.org/10. $1111 / \mathrm{jmi} .12011$.

[24] M. J. Mac, 3D Characterisation of microcracks in concrete, Thesis, Imperial College London, London (2018). doi:https: //doi.org/10.25560/79706.

[25] F. Kleiner, Supported Manual Segmentation (2021). doi: https://doi.org/10.5281/zenodo.5013684

[26] A. Buades, B. Coll, J.-M. Morel, Non-Local Means Denoising, Image Processing On Line 1 (2011). doi:https://doi.org/10. 5201/ipol.2011.bcm\{\textunderscore\}nlm.

[27] H. S. Wong, M. K. Head, N. R. Buenfeld, Pore segmentation of cement-based materials from backscattered electron images, Cement and Concrete Research 36 (6) (2006) 1083-1090. doi: https://doi.org/10.1016/j.cemconres.2005.10.006.

[28] A. G. Shanbhag, Utilization of Information Measure as a Means of Image Thresholding, CVGIP: Graphical Models and Image Processing 56 (5) (1994) 414-419. doi:https://doi.org/10. 1006/cgip.1994.1037.

[29] N. Phansalkar, S. More, A. Sabale, M. Joshi, Adaptive local thresholding for detection of nuclei in diversity stained cytology images, in: 2011 International Conference on Communications and Signal Processing, IEEE, 10.02.2011 - 12.02.2011, pp. 218220. doi:https://doi.org/10.1109/ICCSP. 2011.5739305.

[30] J. Sauvola, M. Pietikäinen, Adaptive document image binarization, Pattern Recognition 33 (2) (2000) 225-236. doi:https: //doi.org/10.1016/S0031-3203(99)00055-2.

[31] J. Schindelin, I. Arganda-Carreras, E. Frise, V. Kaynig, M. Longair, T. Pietzsch, S. Preibisch, C. Rueden, S. Saalfeld, B. Schmid, J.-Y. Tinevez, D. J. White, V. Hartenstein, K. Eliceiri, P. Tomancak, A. Cardona, Fiji: an open-source platform for biological-image analysis, Nature methods 9 (7) (2012) 676682. doi:https://doi.org/10.1038/nmeth. 2019.

[32] S. Torquato, Random heterogeneous materials: Microstructure and macroscopic properties, Vol. v. 16 of Interdisciplinary applied mathematics, Springer, New York, 2002. doi:https: //doi.org/10.1007/978-1-4757-6355-3.

[33] J. Stark, B. Möser, A. Eckart, Neue ansätze der zementhydratation, ZKG International (1 (54)) (2001) 52-60.

[34] A. M. Gajewicz, E. Gartner, K. Kang, P. J. McDonald, V. Yermakou, A 1H NMR relaxometry investigation of gel-pore drying shrinkage in cement pastes, Cement and Concrete Research 86 (2016) 12-19. doi:https://doi.org/10.1016/j.cemconres. 2016.04 .013$.

[35] F. Kleiner, Animation to visualize the electron beam damage induced in calcium silicate hydrate phases (2021). doi:10.5281/ zenodo. 5215574 .

URL https://doi.org/10.5281/zenodo.5215574

[36] J. E. Rossen, Composition and morphology of C-A-S-H in pastes of alite and cement blended with supplementary cementitious materials, Thesis, École Polytechnique Fédérale de Lausanne, Lausanne (2014). doi:https://doi.org/10.5075/ EPFL-THESIS-6294.

[37] J. H. Fitschen, J. Ma, S. Schuff, Removal of curtaining ef- fects by a variational model with directional forward differences, Computer Vision and Image Understanding 155 (2017) 24-32. doi:https://doi.org/10.1016/j.cviu.2016.12.008.

[38] P. D. Tennis, H. M. Jennings, A model for two types of calcium silicate hydrate in the microstructure of Portland cement pastes, Cement and Concrete Research 30 (6) (2000) 855-863. doi : https ://doi.org/10.1016/S0008-8846(00)00257-X.

[39] M. Yio, H. S. Wong, N. R. Buenfeld, 3D Monte Carlo simulation of backscattered electron signal variation across pore-solid boundaries in cement-based materials, Cement and Concrete Research 89 (2016) 320-331. doi:https://doi.org/10.1016/ j.cemconres.2016.09.008.

[40] S. Hemes, G. Desbois, J. L. Urai, B. Schröppel, J.-O. Schwarz, Multi-scale characterization of porosity in Boom Clay (HADESlevel, Mol, Belgium) using a combination of X-ray $\mu$-CT, $2 \mathrm{D}$ BIB-SEM and FIB-SEM tomography, Microporous and Mesoporous Materials 208 (2015) 1-20. doi:https://doi.org/10. 1016/j.micromeso.2015.01.022.

[41] F. Kleiner, C. Rößler, Utilizing Modern FIB/SEM Technology and EDS for 3D Imaging of Hydrated Alite and its Pore Space, in: ERICA-CASH II Final Conference, 2021. 


\title{
Supplementary data: Argon Broad Ion beam sectioning and high resolution scanning electron microscopy imaging of hydrated alite
}

\author{
Florian Kleiner, Christian Matthes, Christiane Rößler \\ F. A. Finger-Institute for Building Materials Science, Bauhaus-University Weimar, 99423 Weimar, Germany
}

\begin{abstract}
This document contains supplementary information (a selection of segmented images prepared using BIB at $-140{ }^{\circ} \mathrm{C}$ and at $20^{\circ} \mathrm{C}$ ) for the article Argon Broad Ion beam sectioning and high resolution scanning electron microscopy imaging of hydrated alite.
\end{abstract}

\section{Introduction}

This document contains the evaluation of 12 additional images as shown in the main article in Figures 16 and 17. The document contains the images, the segmentation result, the evaluation of the pore size distribution (PSD) of every image and the chord density function (CDF) of the segmented pores. All diagrams show the cumulative pore area of each pore diameter bin, since the pore count based histogram and a cumulative pore diameter overvalues the lower pore diameters. For the PSD diagrams, the raw area measurements were used and for the $\mathrm{CDF}$, the measured line lengths were calculated as diameters of a circle.

\section{Additional segmented images}

The following images were acquired as described in the main article. Figures 1 to 4 show images of dense inner C-S-H, which were prepared using Cryo-BIB. The specimens shown in Figures 1 and 2 were prepared at $-140^{\circ} \mathrm{C}$ (raw images can be found at [1]), while the specimens presented in Figure 3 and 4 were prepared at $20^{\circ} \mathrm{C}$ (raw images can be found at [2]). On the left side the raw unedited images are shown, while on the right side, the denoised result image with the result of the semi-automatic segmentation $[3]$ is presented. The areas with a green overlay show the pores, while the blue overlay represents areas manually segmented. The latter were excluded from the pore segmentation since these areas contain large pores, alite or imaging artefacts, which were not subject to the analysis. 


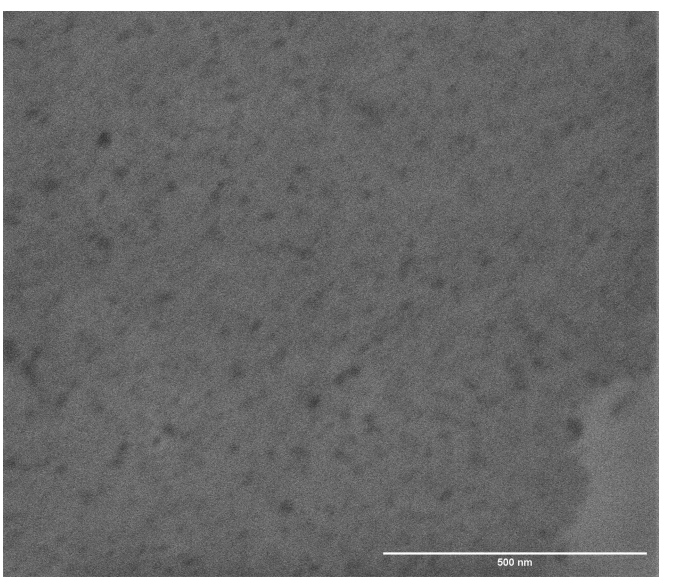

(a) raw image 1

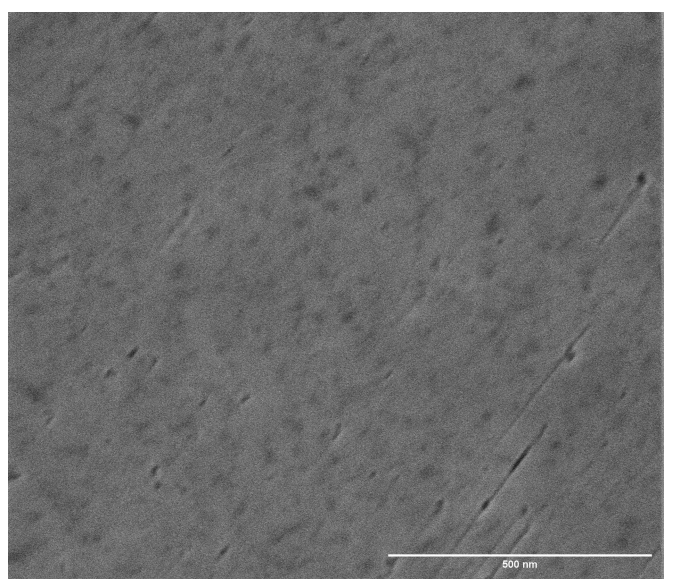

(c) raw image 2

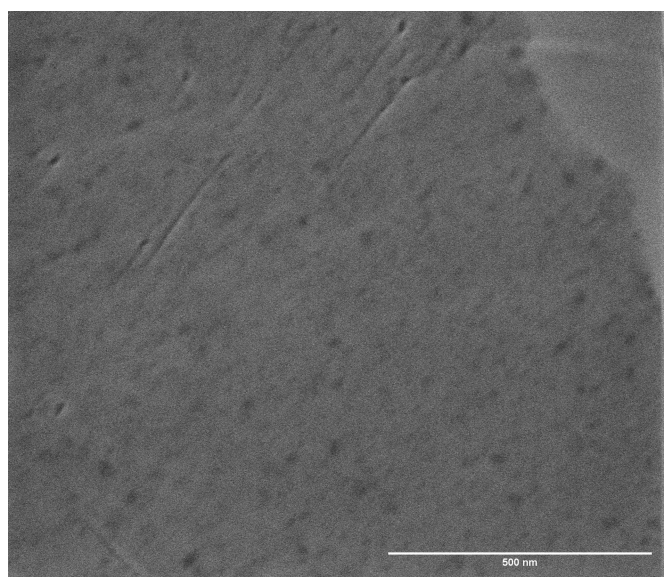

(e) raw image 3

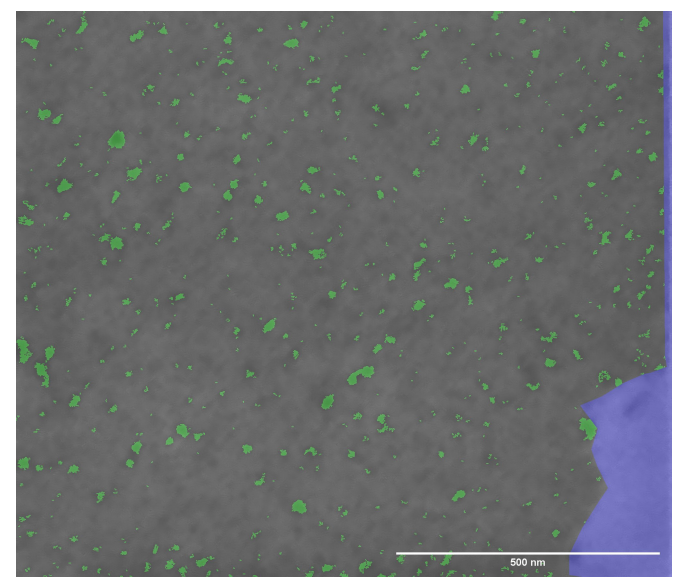

(b) segmented image 1

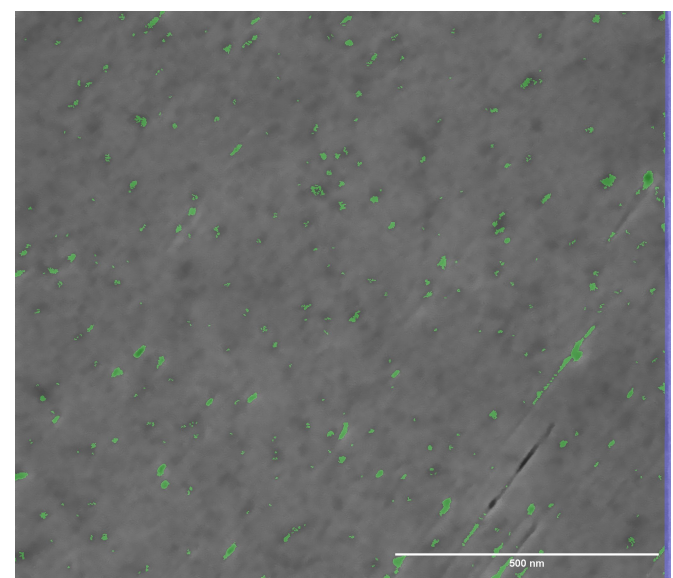

(d) segmented image 2

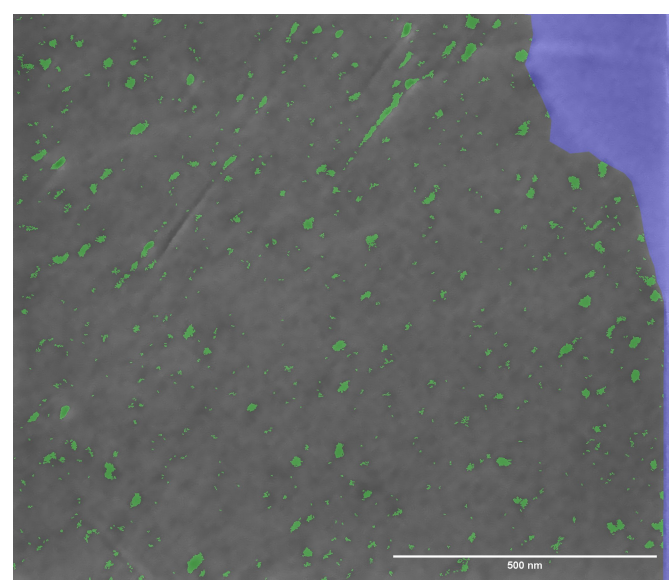

(f) segmented image 3

Figure 1: Segmentation of pores within dense inner C-S-H, BIB at $-140^{\circ} \mathrm{C}$, blue: ignored areas, green: segmented pores. 


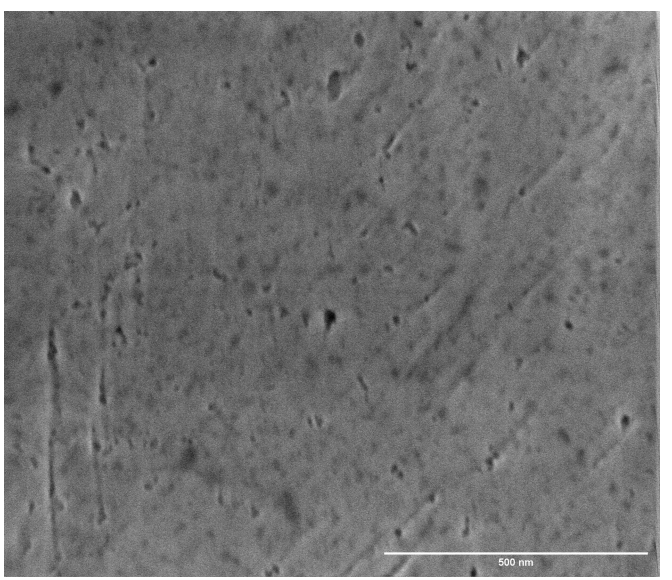

(a) raw image 4

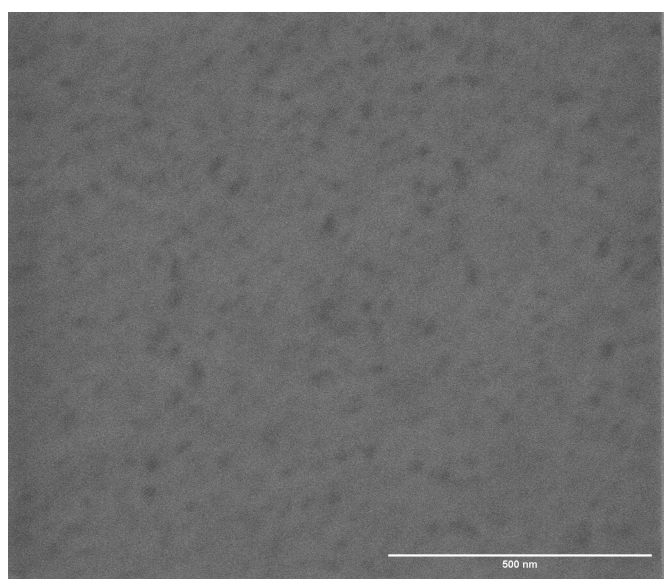

(c) raw image 5

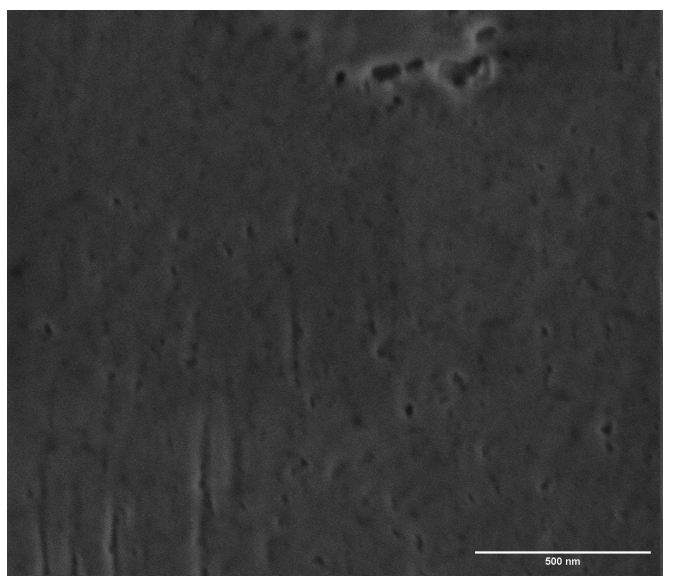

(e) raw image 6

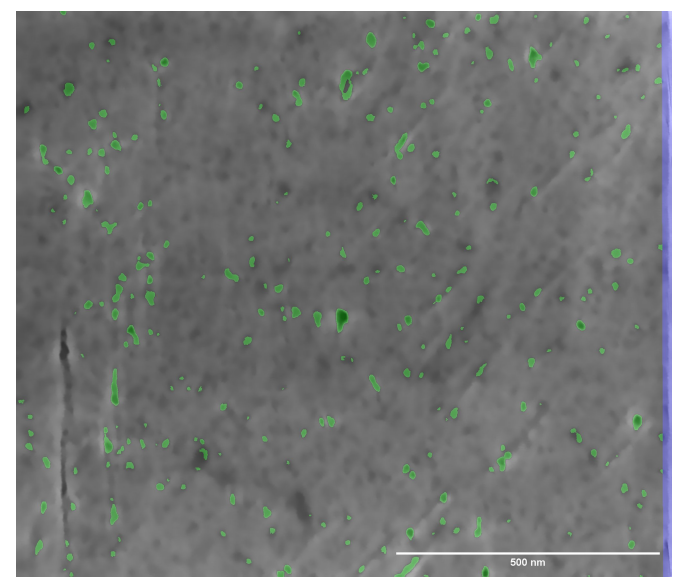

(b) segmented image 4

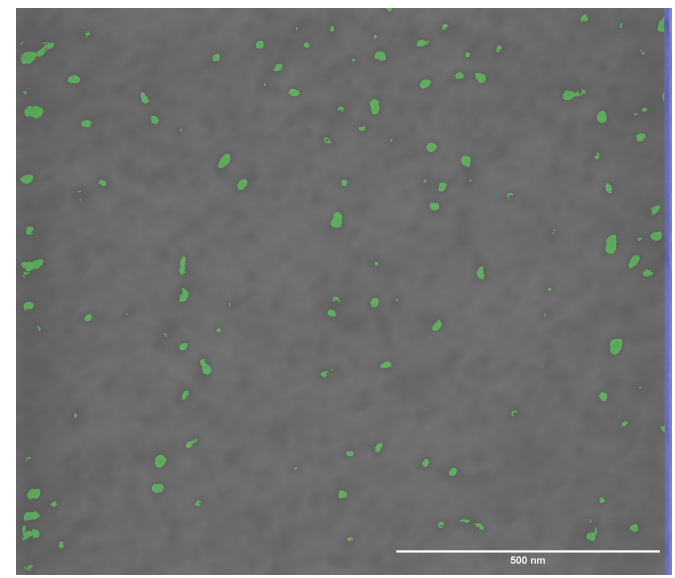

(d) segmented image 5

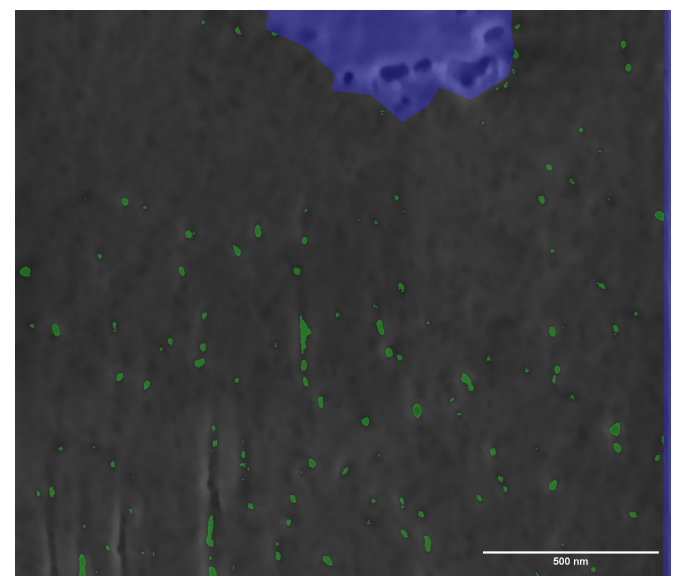

(f) segmented image 6

Figure 2: Segmentation of pores within dense inner C-S-H, BIB at $-140^{\circ} \mathrm{C}$, blue: ignored areas, green: segmented pores. 


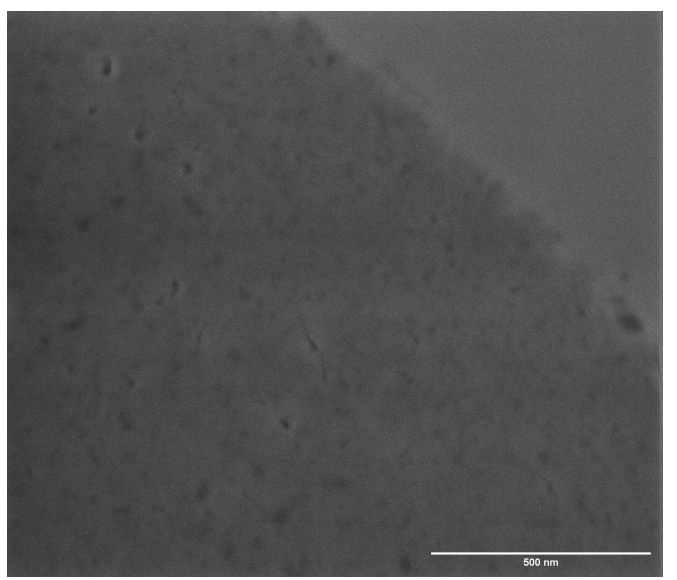

(a) raw image 7

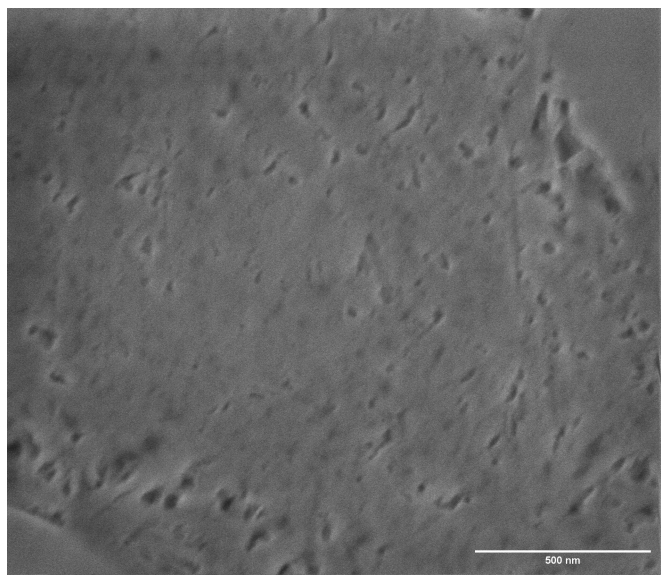

(c) raw image 8

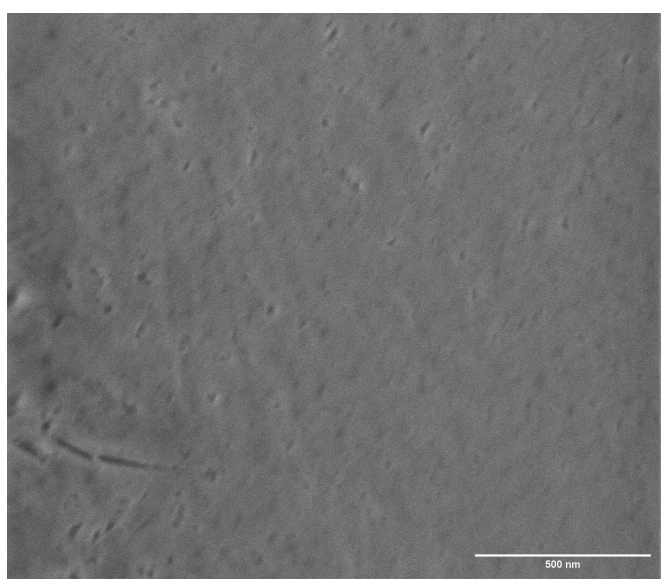

(e) raw image 9

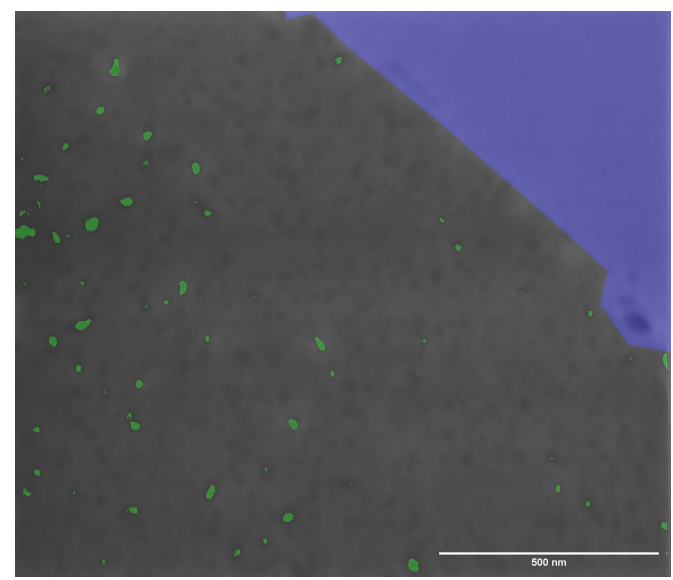

(b) segmented image 7

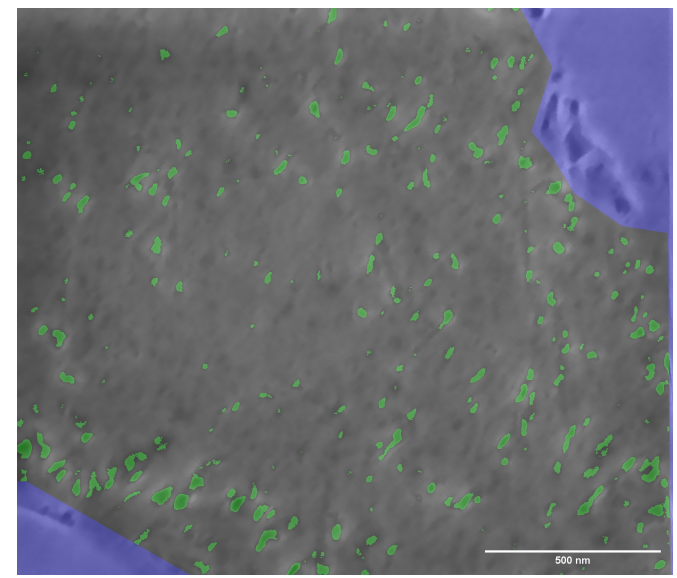

(d) segmented image 8

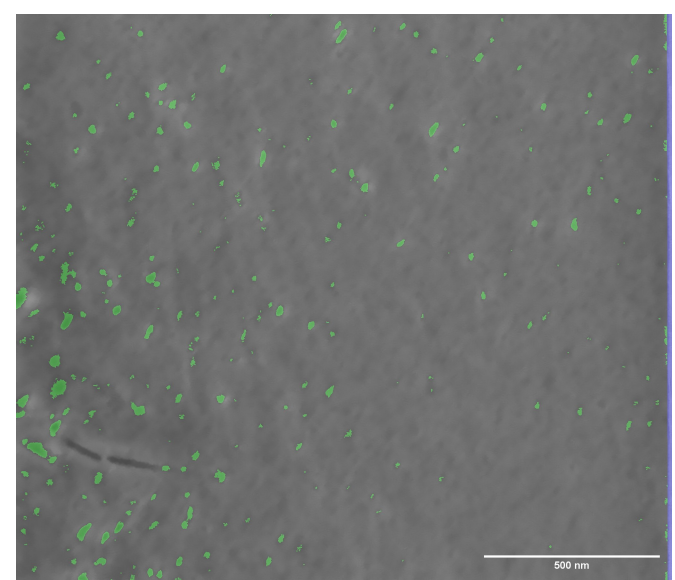

(f) segmented image 9

Figure 3: Segmentation of pores within dense inner C-S-H, BIB at $20^{\circ} \mathrm{C}$, blue: ignored areas, green: segmented pores. 


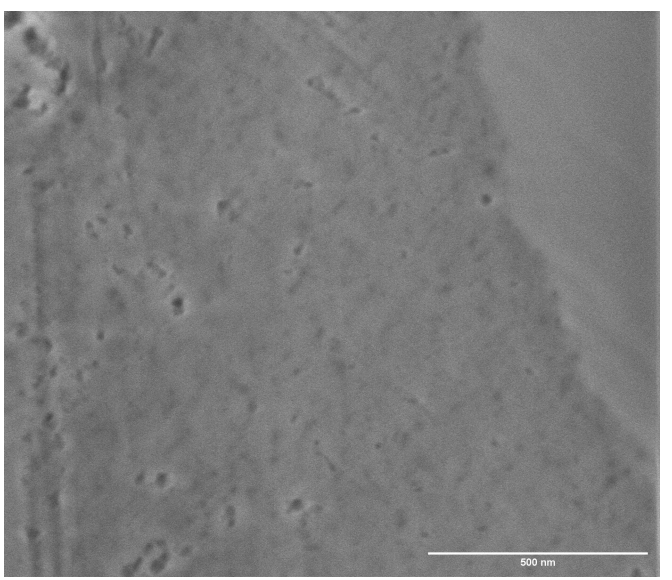

(a) raw image 10

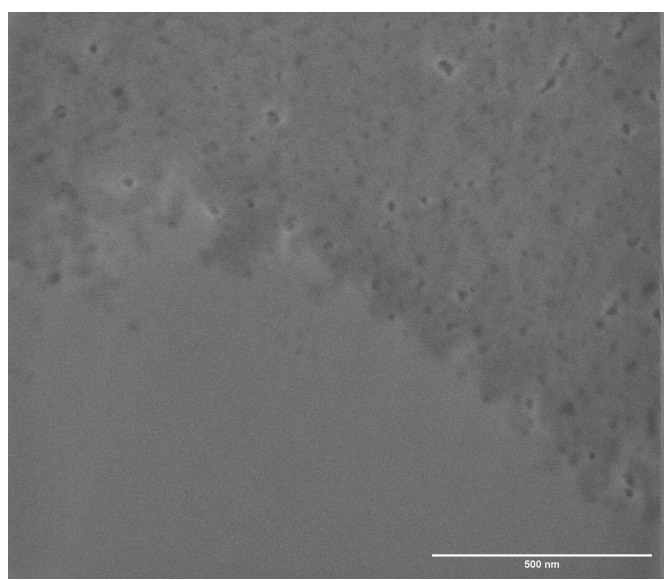

(c) raw image 11

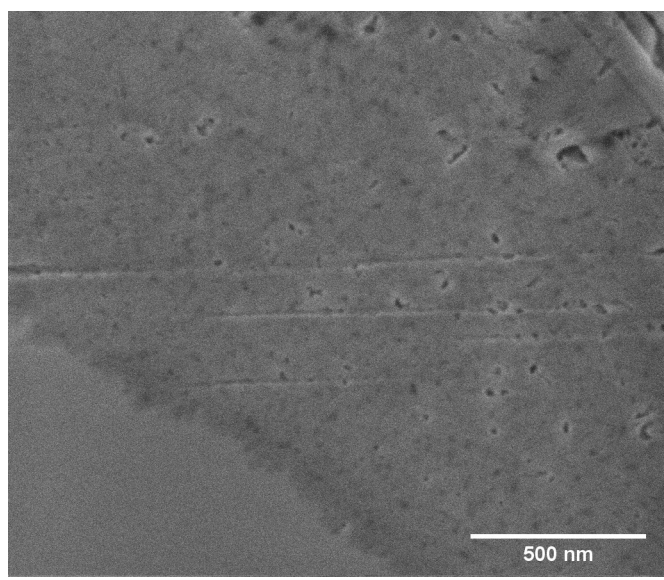

(e) raw image 12

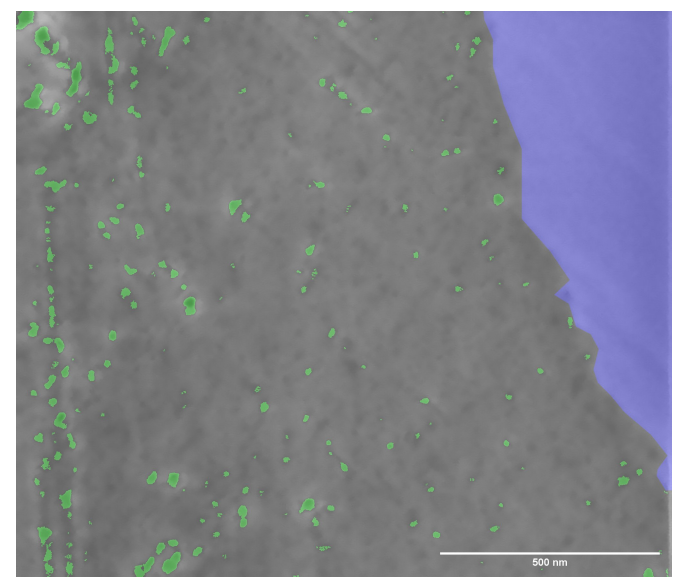

(b) segmented image 10

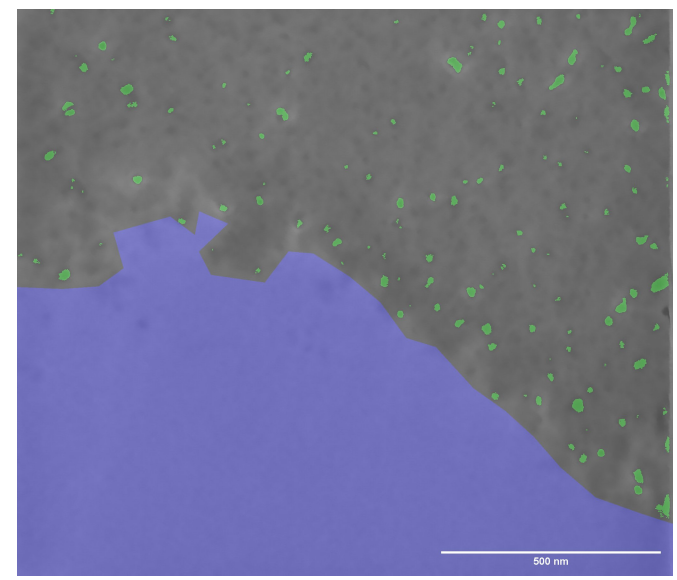

(d) segmented image 11

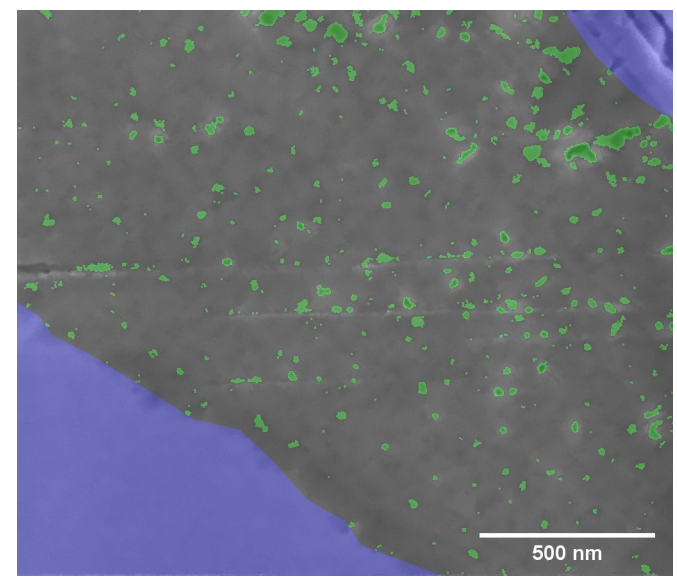

(f) segmented image 12

Figure 4: Segmentation of pores within dense inner C-S-H, BIB at $20^{\circ} \mathrm{C}$, blue: ignored areas, green: segmented pores. 


\section{PSD of the segmented images}

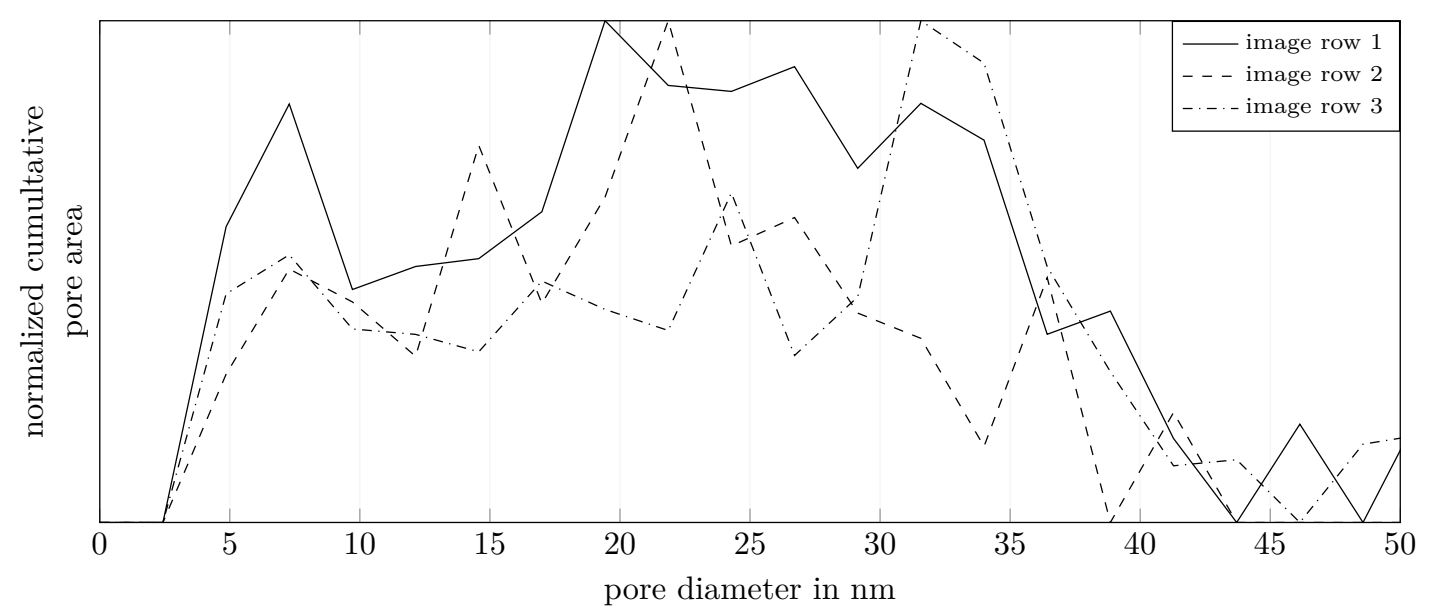

(a) PSD plots for the images in Figure 1

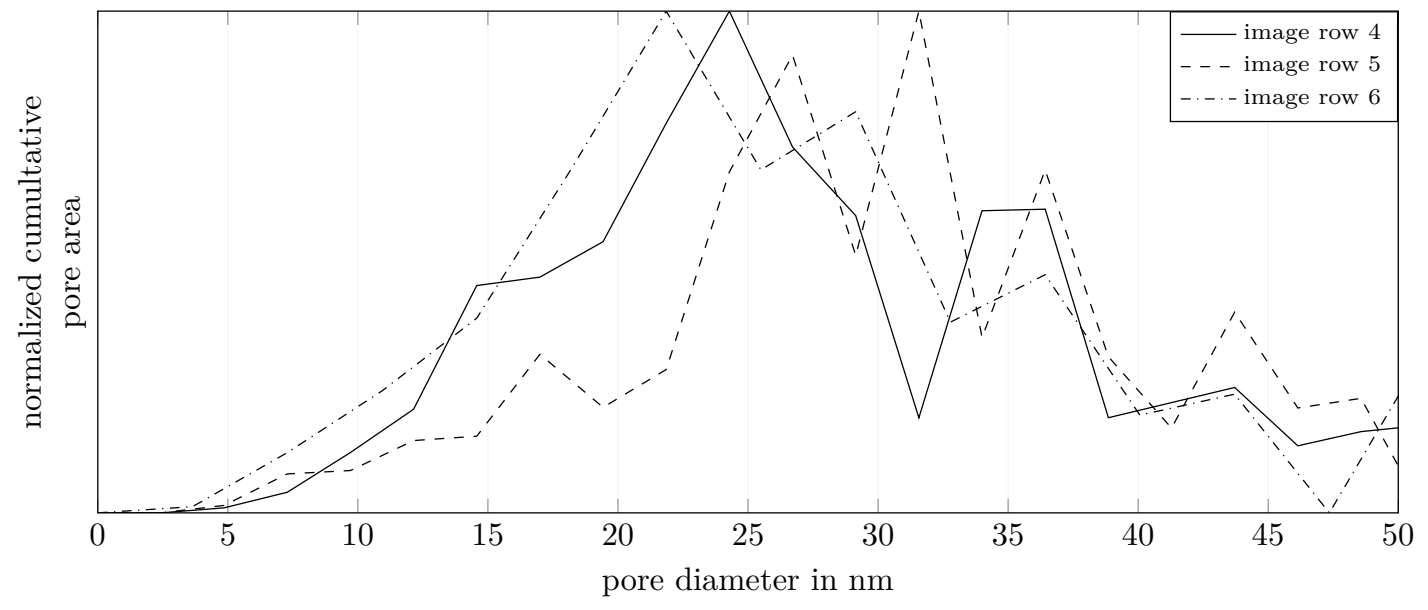

(b) PSD plots for the images in Figure 2

Figure 5: PSD (area) of the images in Figures 1 and 2, (BIB at $\left.-140^{\circ} \mathrm{C}\right)$. 


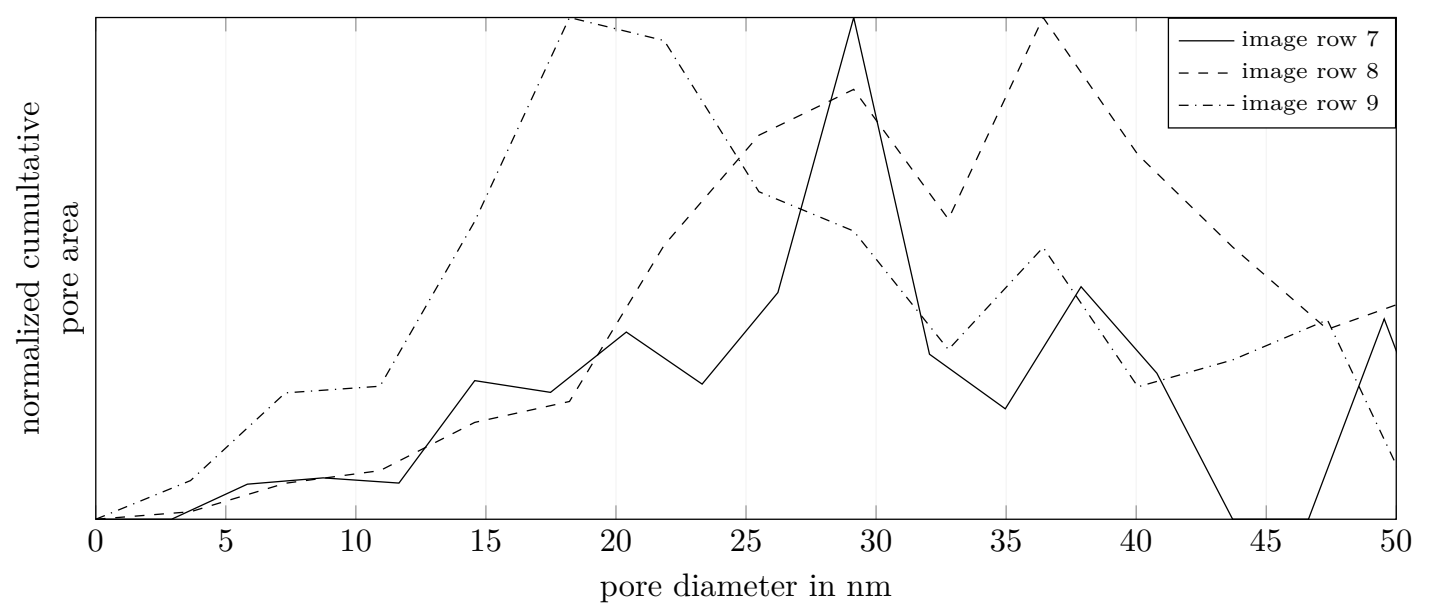

(a) PSD plots for the images in Figure 3

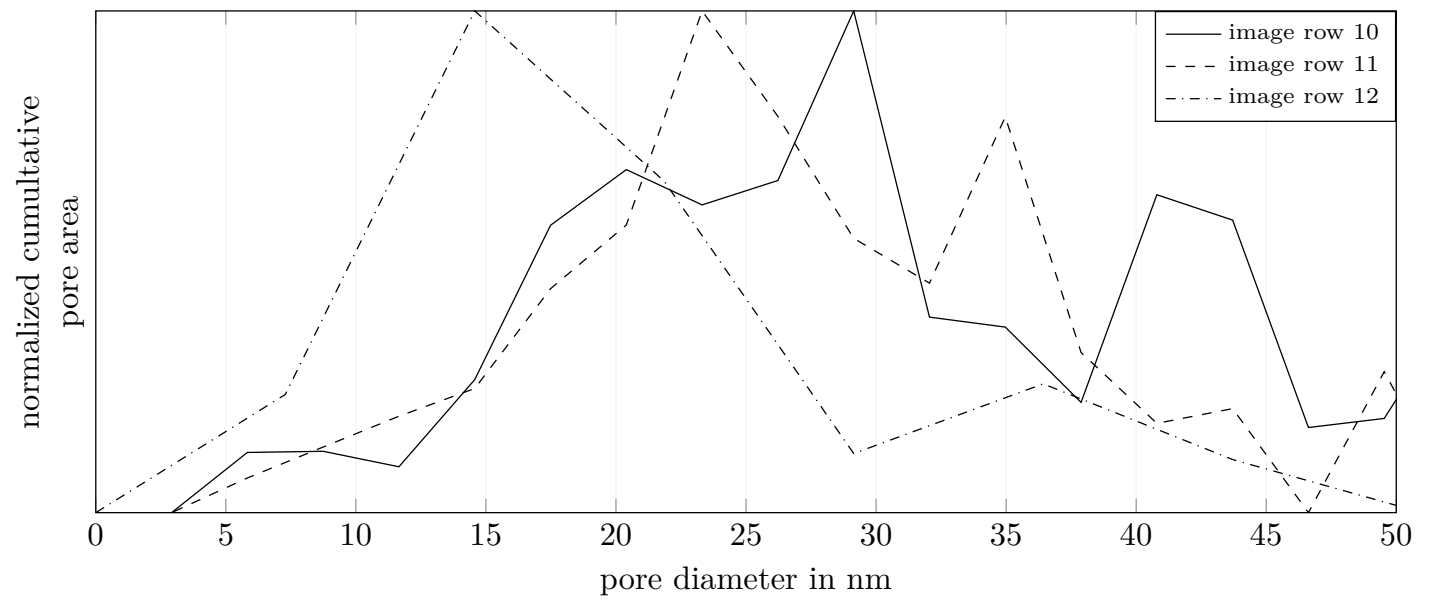

(b) PSD plots for the images in Figure 4

Figure 6: PSD (area) of the images in Figures 3 and 4 , (BIB at $20^{\circ} \mathrm{C}$ ). 


\section{CDF of the segmented images}

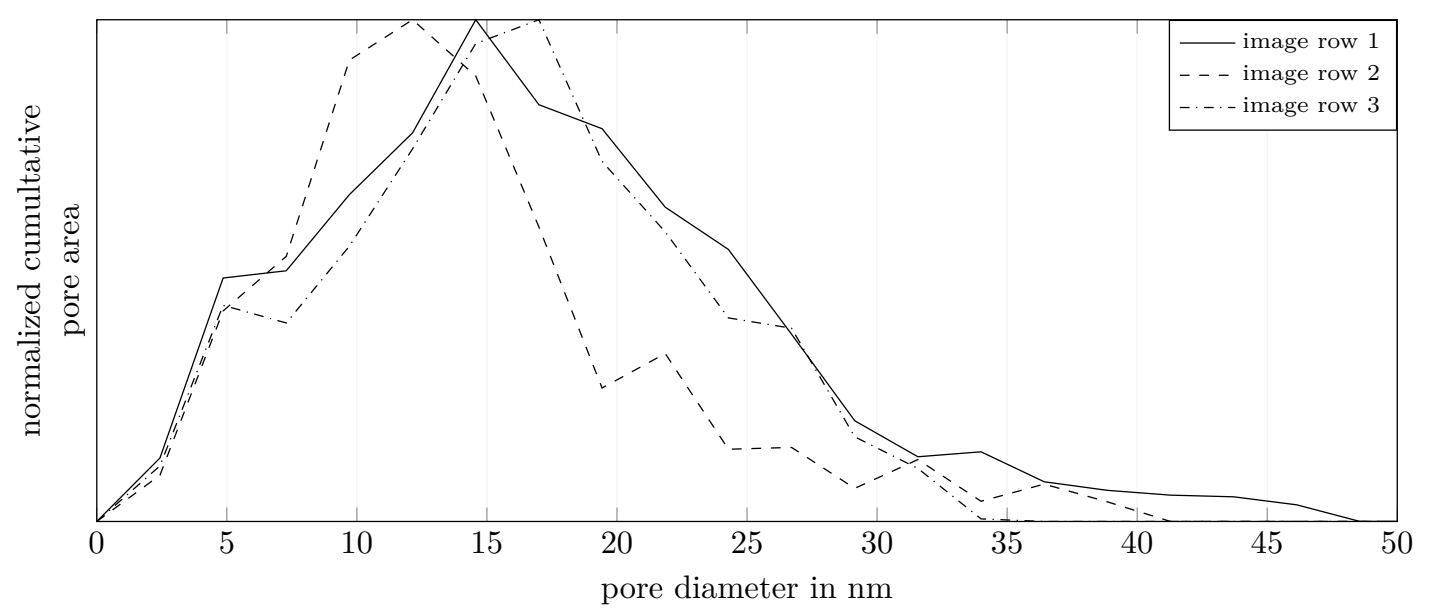

(a) CDF plots for the images in Figure 1

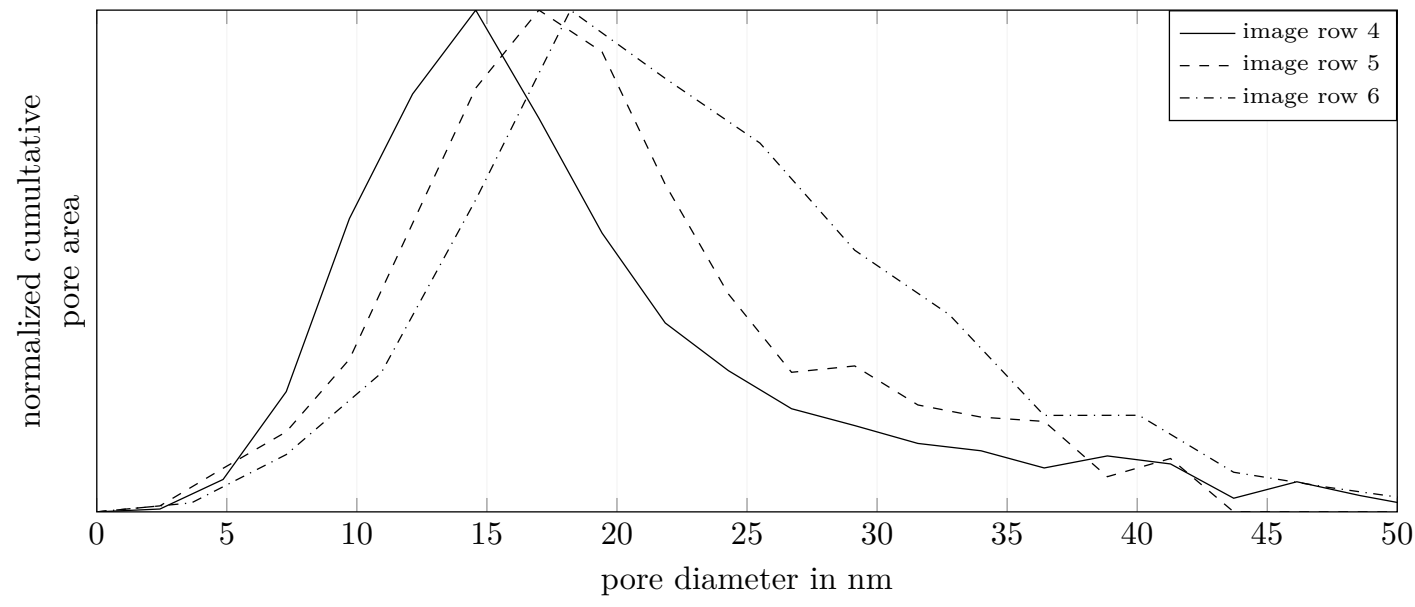

(b) CDF plots for the images in Figure 2

Figure 7: CDF (area) of the images in Figures 1 and 2 , (BIB at $-140^{\circ} \mathrm{C}$ ). 


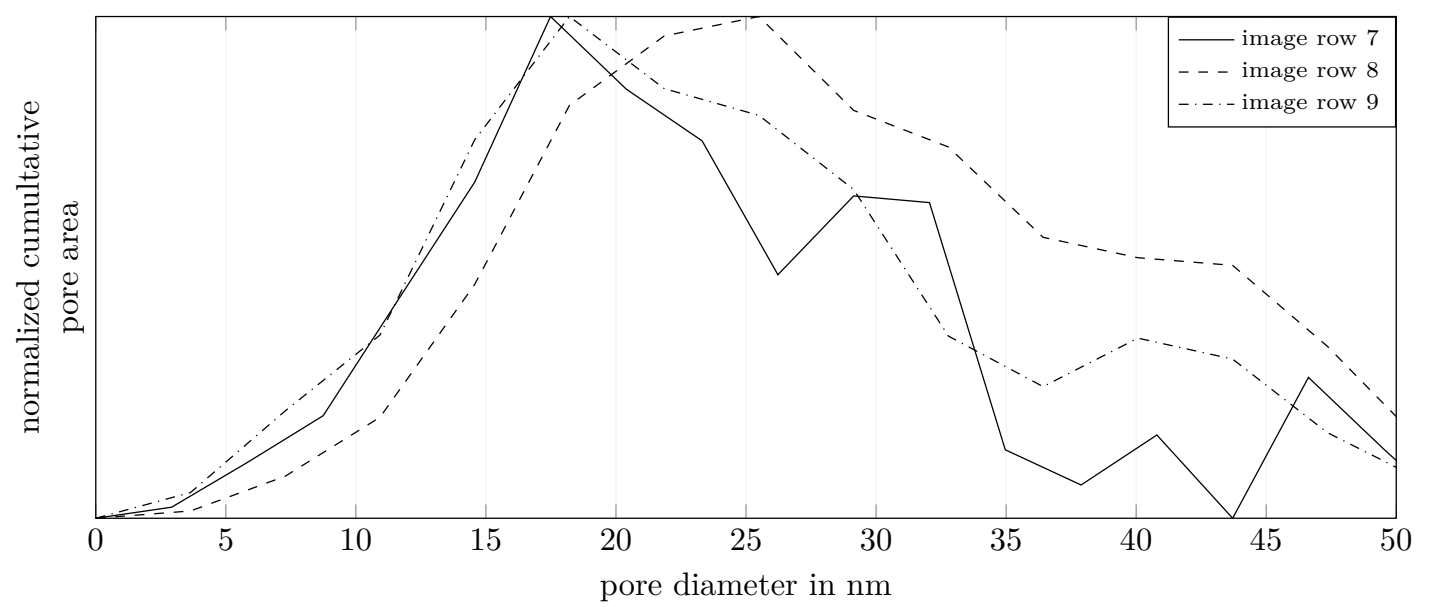

(a) CDF plots for the images in Figure 3

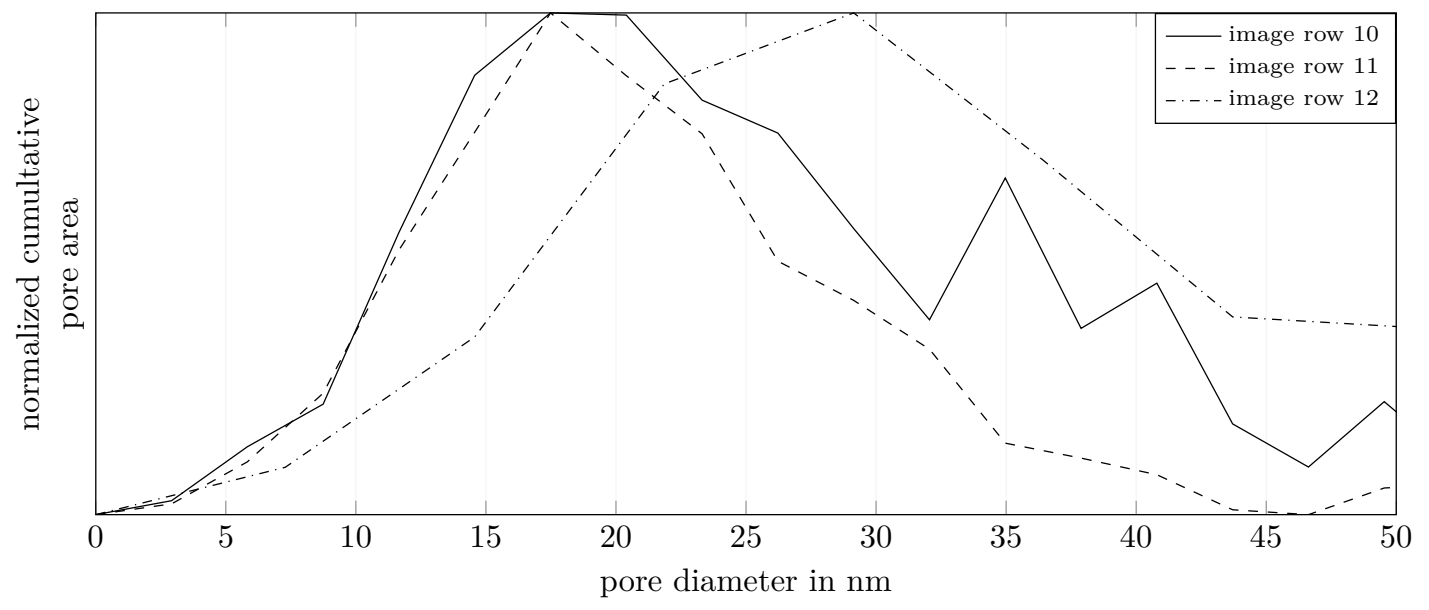

(b) CDF plots for the images in Figure 4

Figure 8: CDF (area) of the images in Figures 3 and $4,\left(\mathrm{BIB}\right.$ at $20^{\circ} \mathrm{C}$ ). 


\section{Basic statistics}

Table 1 shows the peak position (pore diameter) $d_{\max }$ of the CDF-histograms shown in Figures 7 and 8. Since the histograms are composed of bins $b$ (bin width equals 4 times the pixel size of the respective image), the bin center $b_{\text {center }}$ was used as the peak position.

$$
d_{\text {max }}=b_{\text {center }}=\left(b_{\text {lower }}+b_{\text {upper }}\right) / 2
$$

Table 1: Peak position $d_{\max }$ of the $\mathrm{CDF}$ as shown in Figures 7 and 8

\begin{tabular}{cccc}
\hline \multicolumn{2}{c}{ BIB at $-140^{\circ} \mathrm{C}$} & \multicolumn{2}{c}{ BIB at $2{ }^{\circ} \mathrm{C}$} \\
image reference & $d_{\max }$ & image reference & $d_{\max }$ \\
\hline main document, Fig. 16 & $20.5 \mathrm{~nm}$ & main document, Fig. 17 & $20.0 \mathrm{~nm}$ \\
image row 1, Fig. 1(a) & $13.4 \mathrm{~nm}$ & image row 7, Fig. 3(a) & $16.0 \mathrm{~nm}$ \\
image row 2, Fig. 1(c) & $10.9 \mathrm{~nm}$ & image row 8, Fig. 3(c) & $23.7 \mathrm{~nm}$ \\
image row 3, Fig. 1(e) & $15.8 \mathrm{~nm}$ & image row 9, Fig. 3(e) & $16.4 \mathrm{~nm}$ \\
image row 4, Fig. 2(a) & $13.4 \mathrm{~nm}$ & image row 10, Fig. 4(a) & $16.0 \mathrm{~nm}$ \\
image row 5, Fig. 2(c) & $15.8 \mathrm{~nm}$ & image row 11, Fig. 4(c) & $16.0 \mathrm{~nm}$ \\
image row 6, Fig. 2(e) & $16.4 \mathrm{~nm}$ & image row 12, Fig. 4(e) & $25.5 \mathrm{~nm}$ \\
\hline mean & $17.5 \pm 2.8 \mathrm{~nm}$ & mean & $22.7 \pm 5.4 \mathrm{~nm}$ \\
\hline
\end{tabular}

\section{References}

[1] F. Kleiner, Dense inner C-S-H of 28 d hydrated alite, prepared using BIB at $-140^{\circ} \mathrm{C}(2021)$. doi:10.5281/zenodo.5013793.

[2] F. Kleiner, Dense inner C-S-H of 28 d hydrated alite, prepared using BIB at $20^{\circ} \mathrm{C}$ (2021). doi:10.5281/zenodo.5013791.

[3] F. Kleiner, Supported Manual Segmentation (2021). doi:10.5281/zenodo.5013684. 